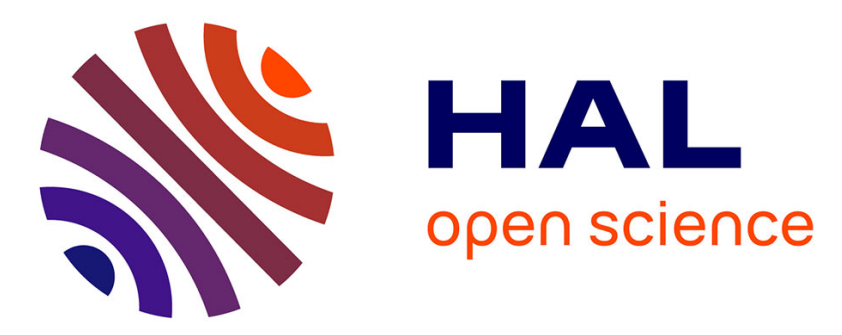

\title{
Rostral cuneiform nucleus and the defence reaction: Direct and indirect midbrain-medullary 5-HT mechanisms in baroreflex inhibition
}

Florence Netzer, Caroline Sévoz-couche

\section{- To cite this version:}

Florence Netzer, Caroline Sévoz-couche. Rostral cuneiform nucleus and the defence reaction: Direct and indirect midbrain-medullary 5-HT mechanisms in baroreflex inhibition. British Journal of Pharmacology, 2021, 178 (8), pp.1819 - 1835. 10.1111/bph.15406 . hal-03182058

\section{HAL Id: hal-03182058 \\ https: / hal.sorbonne-universite.fr/hal-03182058}

Submitted on 26 Mar 2021

HAL is a multi-disciplinary open access archive for the deposit and dissemination of scientific research documents, whether they are published or not. The documents may come from teaching and research institutions in France or abroad, or from public or private research centers.
L'archive ouverte pluridisciplinaire HAL, est destinée au dépôt et à la diffusion de documents scientifiques de niveau recherche, publiés ou non, émanant des établissements d'enseignement et de recherche français ou étrangers, des laboratoires publics ou privés. 


\title{
Rostral cuneiform nucleus and the defence reaction: Direct and indirect midbrain-medullary 5-HT mechanisms in baroreflex inhibition
}

\author{
Florence Netzer ${ }^{1}$ | Caroline Sévoz-Couche ${ }^{2}$
}

${ }^{1}$ INSERM U894, Centre of Psychiatry and Neurosciences, Paris, France

${ }^{2}$ Sorbonne Université, INSERM, UMRS1158, Neurophysiologie Respiratoire, Expérimentale et Clinique, Paris, France

\section{Correspondence}

Caroline Sévoz-Couche, Sorbonne University, INSERM, UMRS1158, Neurophysiologie Respiratoire, Expérimentale et Clinique, $91 \mathrm{Bd}$ de l'hôpital, 75013, Paris, France.

Email: caroline.sevoz-couche@upmc.fr

Funding information

Institut National de la Santé et de la Recherche Médicale; Association Sorbonne Université
Background and Purpose: Activation of the defence reaction inhibits the baroreflex response via the intermediate rostro-ventromedial medulla (B3 raphé) and nucleus tractus solitarius (NTS). Our aim was to determine whether and how baroreflex inhibition, induced by the disinhibition of the rostral cuneiform nucleus (part of the defence pathway), involves 5-HT neurons in $\mathrm{B} 3$ and $5-\mathrm{HT}_{3}$ receptors in the NTS.

Experimental Approach: We performed immunohistochemistry and anatomical experiments to determine whether raphé $5-\mathrm{HT}$ cells expressing Fos were directly targeted by the rostral cuneiform nucleus. The effect of blocking raphe 5-HT neurotransmission and NTS $5-\mathrm{HT}_{3}$ receptors on cuneiform-induced inhibition of the baroreflex cardiac response were also analysed.

Key Results: Bicuculline, microinjected into the rostral cuneiform nucleus, induced an increase of double-labelled Fos-5-HT-IR cells in both the lateral paragigantocellular nucleus (LPGi) and raphé magnus. The anterograde tracer Phaseolus vulgaris leucoaggutinin injected into the rostral cuneiform nucleus revealed a dense projection to the LPGi but not raphé magnus. Cuneiform-induced baroreflex inhibition was prevented by $\mathrm{B} 3$ injection of 8-OH-DPAT, a selective $5-\mathrm{HT}_{1 \mathrm{~A}}$ receptor agonist. Cuneiform disinhibition also failed to inhibit the baroreflex bradycardia after NTS microinjection of the $5-\mathrm{HT}_{3}$ receptor antagonist granisetron and in $5-\mathrm{HT}_{3}$ receptor knockout mice.

Conclusion and Implications: The rostral cuneiform nucleus participates in the defence inhibition of the baroreflex bradycardia via direct activation of the LPGi and via a projection to the raphé magnus to activate NTS $5-\mathrm{HT}_{3}$ receptors and inhibit second-order baroreflex neurons. These data bring new insights in primary and secondary mechanisms involved in vital baroreflex prevention during stress.

\section{KEYWORDS}

autonomic, baroreflex, caudal raphé, cuneiform, 5-HT, stress 


\section{$1 \mid$ INTRODUCTION}

Arterial baroreflex represents a powerful negative feedback control mechanism to maintain BP homeostasis. Activation of the major arterial baroreceptors (aortic and carotid origin) following an increase in BP causes immediate parasympathetic cardiovagal excitation. The rapid $(<1 \mathrm{~s})$ decrease in heart rate $(H R)$ will secondarily, through a decrease in cardiac output, cause a decrease in BP after a few seconds (baroreflex loop) (Vaschillo et al., 2006). Under specific circumstances, such as during the defence reaction, blood flow is redistributed between organs, increasing blood supply to the skeletal muscles, heart and brain. This redistribution is the consequence of vessel constriction, increase in venomotor tone (Martin et al., 1996) and increase in cardiac output, mainly due to an increase in HR (Crestani, 2016). Stroke volume was not affected (Schulte \& Neus, 1983; Wilson \& Crandall, 2011) or only slightly increased (Anderson \& Brown, 1967; Lindvall et al., 1991) during stress. Altogether, these factors produce an increase in BP (Nosaka, 1996). This would trigger a baroreflex bradycardia. However, this reflex response would counteract the vital increase in cardiac output necessary for muscles oxygenation and the body's reactions during stress. Several studies found that the cardiovagal effect on the heart (bradycardia) is suppressed during the defence reaction (Comet et al., 2004, 2005; Nosaka, 1996; Sévoz-Couche et al., 2003).

The nucleus tractus solitarius (NTS) plays a major role in the reduction in the baroreflex cardiovagal response during the defence reaction. Specific blockade of local $5-\mathrm{HT}_{3}$ receptors, the only ligand-gated ion channel among 5-HT receptors (Hoyer, 1990), prevents the reflex cardiac inhibition induced by activation of the dorsolateral periaqueductal grey matter (PAG, Comet et al., 2004, 2005), a key region involved in the defence reaction (Bandler \& Carrive, 1988). The possible source of 5-HT released into the NTS to activate these $5-\mathrm{HT}_{3}$ receptors, following dorsolateral PAG activation, is the intermediate rostro-ventromedial medulla region (intermediate B3 region), including the lateral paragigantocellular nucleus (LPGi) and the raphé magnus (RMg), as 5-HT neurons in the LPGi and the RMg (but not other raphé nuclei) express Fos protein after dorsolateral PAG activation (Bernard et al., 2008).

The rostral cuneiform nucleus may also be part of the defence reaction as suggested by observations made by Netzer et al. (2011); (i) the baroreflex inhibition induced by stimulation of the dorsomedial nucleus of the hypothalamus, a key region of the defence reaction (DiMicco et al., 1996), was prevented by the chemical inhibition of the rostral cuneiform following local administration of muscimol and (ii) disinhibition of the latter nucleus through blockade of GABAergic inputs (bicuculline), which caused an inhibitory effect on baroreflex response which could be prevented by dorsolateral PAG blockade.

These observations suggested that, as for the dorsolateral PAG, B3 activation could play a key role in the baroreflex inhibition obtained during cuneiform disinhibition. To answer this question, we performed double immunolabelling in the $\mathrm{B} 3$ region (LPGi and $\mathrm{RMg}$ ), as well as in other raphé nuclei (raphé dorsalis [RDr], raphé pallidus

\section{What is already known}

- The baroreflex bradycardia is inhibited during the defence reaction to acute fear.

- This inhibition is a key step for maximal oxygenation of skeletal muscles.

\section{What this study adds}

- The rostral cuneiform disinhibition induces activation of 5-HT neurons in the intermediate B3 region only.

- The release of 5-HT targets $5-\mathrm{HT}_{3}$ receptors in the NTS.

\section{What is the clinical significance}

- Multiple protective medullary pathways are involved in the vital stress-induced inhibition of the baroreflex response.

- $5-\mathrm{HT}_{3}$ receptors may be a target for limitation of cardiac events due to stress.

[RPa] and raphé obscurus [ROb]). We analysed the expression of Fos protein in $5-\mathrm{HT}$ immunoreactive (Fos-5-HT-IR) cells in these nuclei after injection of the $\mathrm{GABA}_{A}$ antagonist bicuculline into the rostral cuneiform nucleus. Despite the fact that activation of $5-\mathrm{HT}$ neurons was detected in the entire B3 intermediate region following the dorsolateral PAG stimulation (Bernard et al., 2008), there is a direct link from the latter to the LPGi but not the RMg (Babic \& Ciriello, 2004). This raised the possibility that activation of passing fibres, like those from the cuneiform nucleus (Netzer et al., 2011), may have been at the origin of dorsolateral PAG-induced 5-HT activation in the RMg. To answer this question, we injected an anterograde tracer (Phaseolus vulgaris leucoaggutinin) into the rostral cuneiform nucleus to determine whether descending projections towards the intermediate B3 region (including the $\mathrm{RMg}$ ) could be found. To definitely establish whether raphé $5-\mathrm{HT}$ neurons are activated by rostral cuneiform disinhibition and that NTS $5-\mathrm{HT}_{3}$ receptors are involved in defenceinduced baroreflex inhibition, we performed the following pharmacological experiments. We analysed the baroreflex response reduction obtained normally and during rostral cuneiform disinhibition, before and after (i) local raphé inactivation caused by microinjections of the $\mathrm{GABA}_{A}$ receptor agonist muscimol, (ii) raphé 5-HT neuron inhibition using microinjections of $5-\mathrm{HT}_{1 \mathrm{~A}} / 5-\mathrm{HT}_{7}$ receptor agonist 8-OH-DPAT and (iii), blockade of NTS $5-\mathrm{HT}_{3}$ receptors by microinjections of granisetron in rats or by comparing effect of rostral cuneiform disinhibition in wild-type (WT) with those in $5-\mathrm{HT}_{3}$ receptor knockout mice. 


\section{2 | METHODS}

\section{$2.1 \mid$ Animals}

All animal care and experimental procedures followed institutional guidelines, which comply with national and international law policies (Council Directive 87-848, October 19, 1987, Ministère de l'Agriculture et de la Forêt, Service Vétérinaire de la Santé et de la Protection Animale; Permission No. 75-855 to C.S.-C.). Animal studies are reported in compliance with the ARRIVE guidelines (Percie du Sert et al., 2020) and with the recommendations made by the British Journal of Pharmacology (Lilley et al., 2020).

Experiments were performed using 52 male Sprague-Dawley rats (RRID:MGI_5651135) (330-350 g) and 12 male mice (25 g) homozygous Htr3a KO $(n=6)$ and WT littermates $(n=6)$ born from heterozygous mutants on a C57BL/6J (RRID:MGI_5811150) genetic background ( $>10$ generations) and genotyped as described by Zeitz et al. (2002). Animals were kept under controlled environmental conditions (ambient temperature: $21 \pm 1^{\circ} \mathrm{C}, 60 \%$ relative humidity, unrestricted access to food and water, and alternate 12-h light/12-h dark cycles) for a least 1 week after delivery from the breeding centre (CER Janvier, Le Genest-Saint-Isle, France). Studies were designed to generate groups of equal size, using randomization and blinded analysis, accordingly to recommendations of the British Journal of Pharmacology on experimental design and analysis (Curtis et al., 2018).

\section{2 | Sustained chemical disinhibition of the rostral cuneiform nucleus to induce Fos expression in raphé nuclei}

\subsection{1 | Rostral cuneiform nucleus long-term disinhibition}

Twelve rats were anaesthetized with chloral hydrate $\left(400 \mathrm{mg} \cdot \mathrm{kg}^{-1}\right.$, i.p.) for immunohistological experiments. The size of the samples was based on previous experiments (Bernard et al., 2008). The depth of anaesthesia was assessed regularly by pinching a hind paw and monitoring the stability of the arterial BP and HR recordings, and further injections (i.v.) of chloral hydrate were given as necessary. The animals were allowed to breathe spontaneously. Rectal temperature was maintained at $37^{\circ} \mathrm{C}$ with a thermostatically controlled heating blanket. The femoral vein was catheterized for the administration of additional anaesthesia or drugs. Mean BP (MBP) was monitored via a femoral arterial catheter connected to a pressure transducer and DC amplifier (Gould, Courtaboeuf, France). The ECG was recorded using stainless steel pins placed subcutaneously into forepaws and hind paws. Signals were amplified and filtered (Universal Amplifier, Gould). HR was computed from the ECG (R-wave pulses) and displayed as mean frequency per minute (bin size $=1 \mathrm{~s}$ ). Lidocaine (xylocaine ${ }^{\circledR} ; 5 \mathrm{mg} \cdot \mathrm{kg}^{-1}$ ) was injected s.c., at the posterior aspect of the neck at the beginning of all surgery to provide local anaesthesia.
Briefly, anesthetized rats $(n=6)$ were placed in a stereotaxic frame with the head fixed in the flat skull positionn, two unilateral (left) microinjections (with 10-min interval) at rostral cuneiform sites (-8.2 to $-8.5 \mathrm{~mm}$ from bregma, $2 \mathrm{~mm}$ lateral and $5 \mathrm{~mm}$ ventral to the surface of the brain; Netzer et al., 2011) filled with bicuculline methiodide (50 pmol per $50 \mathrm{nl}$ ) were necessary to maintain cuneiform activation for $20 \mathrm{~min}$, as confirmed by a sustained and stable increase in MBP and HR. These variables were high but stable after bicuculline administration and started to come back to baseline after 20 min (Netzer et al., 2011). Activation of the defence reaction was identified by the observation of somatic responses such as mydriasis, vibrissae and body movements, and tail erection. Sham animals $(n=6)$ received vehicle treatment (saline). No somatic, MBP and HR responses were observed.

\subsection{2 | Visualization of Fos and/or 5-HT immunoreactive (Fos-IR and/or 5-HT-IR) neurons}

Two hours after the end of the second microinjection of bicuculline or saline into the rostral cuneiform, anaesthetized rats were perfused intracardially. The brain was removed and cryoprotected as described above. Coronal frozen sections ( $50 \mu \mathrm{m}$ thick) of the whole brainstem were collected in four containers filled with PBS, allowing their parallel processing as serial groups of floating sections.

Processing is described in Data S1. Neurons were observed under bright-field illumination in $50-\mu \mathrm{m}$-thick coronal sections $(200 \mu \mathrm{m}$ apart) in regions containing $5-\mathrm{HT}$ neurons (the LPGi, the RMg, the $\mathrm{RPa}$, the ROb and the RDr nuclei). The location of brainstem nuclei containing 5-HT neurons was based on observation of adjacent Nissl-stained sections.

Brain tissue sections were analysed after careful individual examination of each neuron at high magnification $(\times 40)$. The outline of the section and the main structures were drawn at low magnification ( $\times 4$ and $\times 10$ ), the computer providing continuous synchronization between plotting and section location during moving or magnification changes. For each animal, a total of four brain sections for each region of interest were analysed under bright-field illumination. Neurons were plotted using Mercator software (RRID:SCR_014493) (Explora Nova, La Rochelle, France). The computer was connected to (i) a CCD colour video camera that captured images and supplied red, green and blue output and (ii) an XY stage microscope stage controller that sent the micrometric location of the section boundaries to the computer.

\section{3 $\quad$ Anterograde tracing of rostral cuneiform nucleus efferents to the $\mathrm{B} 3$ region}

\subsection{1 | Tracer injection}

Ten rats were anaesthetized with chloral hydrate $\left(400 \mathrm{mg} \cdot \mathrm{kg}^{-1}\right.$, i.p.) for anatomical experiments. The size of the sample was based on previous experiments (Netzer et al., 2011). The depth of anaesthesia was 
assessed regularly by pinching a hind paw and monitoring the stability of the arterial BP and HR recordings and further injections (i.v.) of chloral hydrate were given as necessary. Rectal temperature was maintained at $37^{\circ} \mathrm{C}$ with a thermostatically controlled heating blanket. The animals were allowed to breathe spontaneously. To provide local anaesthesia, lidocaine (xylocaine ${ }^{\circledR} ; 5 \mathrm{mg} \cdot \mathrm{kg}^{-1}$ ) was injected s.c. at the posterior aspect of the neck, at the beginning of the surgery, and meloxicam (metacam®; $1 \mathrm{mg} \cdot \mathrm{kg}^{-1}$ ) at the end of surgery. Anaesthetized animals were placed in a stereotaxic frame with the head fixed in the flat skull position. Application of Phaseolus vulgaris leucoagglutinin lectin (PHA-L) was made by passing direct current (2-6 $\mu \mathrm{A}$, electrode tip positive) through a micropipette directed to the left rostral cuneiform nucleus (see above) for $20 \mathrm{~s}$ per 30 -s period, for $20 \mathrm{~min}$ (Netzer et al., 2011). Following a post-operative period of 15 days, animals were deeply anaesthetized with pentobarbitone (200 mg. $\mathrm{kg}^{-1}$, i.p.). They were then perfused transcardially and the brain was removed, and cryoprotected in a $20 \%$ sucrose solution overnight. Frozen sections ( $50 \mu \mathrm{m}$ thick) of the whole brainstem were collected in four containers filled with PBS, allowing their parallel processing as three serial groups of free-floating sections.

\subsubsection{Immunohistochemical processing for anterograde labelling}

Processing is described in detail in Data S1.

Labelled fibres in the regions identified in the first set of experiments (identification of double-labelled Fos-5-HT-IR cells) were observed under bright-field illumination in coronal sections. Terminals were differentiated from fibres of passage using classical morphological criteria (ramification, varicosities, thickness and pattern). All immuno-related procedures involved comply with the editorial on immunoblotting and immunohistochemistry (Alexander et al., 2018).

\section{4 | Pharmacological experiments}

\subsection{1 | Acute rostral cuneiform disinhibition in rats and mice}

Animals were anaesthetized with urethane $\left(1.5 \mathrm{~g} \cdot \mathrm{kg}^{-1}\right.$, i.p.) to ensure similar experimental conditions as those performed previously (Bernard et al., 2008; Gau et al., 2009; Netzer et al., 2011). The femoral vein was catheterized, and MBP and HR were recorded as mentioned above. Anaesthetized animals were placed in a stereotaxic frame with the head fixed in the flat skull position. The size of the samples was based on previous experiments (Bernard et al., 2008; Netzer et al., 2011; Zafar et al., 2018). Briefly, rostral cuneiform disinhibition was caused by left microinjection of bicuculline in rats (50 pmol per $50 \mathrm{nl}, n=30, n=6$ in each of 5 groups: [i] B3 muscimol, [ii] B3 8-OH-DPAT, [iii] B3 saline, [iv] NTS granisetron, and [v] NTS saline) and mice ( 25 pmol per $25 \mathrm{nl}, n=6 \mathrm{WT}$ and $n=65-\mathrm{HT}_{3}$ knockout animals).

\subsection{2 | Evaluation of the baroreflex sensitivity in control and experimental conditions in rats and mice}

In the control condition, baroreceptors were unloaded using the vasodilator sodium nitroprusside (SNP, $100 \mu \mathrm{g} \cdot \mathrm{kg}^{-1}$, i.v.) followed by baroreceptor stimulation using the vasoconstrictor phenylephrine (PE, $10 \mu \mathrm{g} \cdot \mathrm{kg}^{-1}$, i.v.) (Sévoz-Couche et al., 2013). Administration of nitroprusside followed by phenylephrine allowed the generation of baroreceptor function curves (changes in HR as a function of BP changes) by fitting the data to the sigmoid logistic function: $Y=$ Bottom $+($ Top - Bottom $) /(1+\exp ((V 50-X) /$ Slope $)$, using Prism (RRID:SCR_002798) (GraphPad Software Inc., La Jolla, CA, USA), where Top - Bottom was the maximal baroreflex range. Rectilinear baroreflex slopes were calculated from the baroreceptor curves and considered as reflect of the baroreflex sensitivity (BRS, expressed as $\mathrm{bpm} \cdot \mathrm{mmHg}^{-1}$ ).

In the same animal (rat or mice), after $15 \mathrm{~min}$, left rostral cuneiform disinhibition was performed. When BP increase was stable (2-4 min after bicuculline), SNP + PE was administered again (experimental condition).

To eliminate the influence of defence reaction-induced tachycardia on the cardiac baroreflex responses, all animals used in the following experiments were pretreated with the $\beta$-adrenoceptor antagonist atenolol ( $1 \mathrm{mg} \cdot \mathrm{kg}^{-1}$, i.v., $20 \mathrm{~min}$ before the first baroreflex induction).

\subsection{3 | Microinjections into the B3 region and NTS in rats}

A micropipette connected to a Hamilton microsyringe was lowered into the target areas for the first 100-nl injection and refilled with the same volume for the second injection; the time interval between the two microinjections was less than $1 \mathrm{~min}$.

Bilateral microinjections of bodipy TMR-X conjugate muscimol (500 pmol per $100 \mathrm{nl}$ ), a selective $\mathrm{GABA}_{\mathrm{A}}$ receptor agonist (Johnston et al., 1968), were made in $B 3$ region identified in immunohistological experiments (i.e. between -11.0 and $11.5 \mathrm{~mm}$ from bregma, 0 to $1 \mathrm{~mm}$ lateral and 9.0 to 9.5 ventral to the surface of the cerebellum). The injection sites were precisely located owing to the orange light emission $(572 \mathrm{~nm}$ ) of the fluorophore linked to muscimol. 5-HT cells were visualized in coronal sections by the green fluorescent emission $(519 \mathrm{~nm})$ of Alexa Fluor goat 488 anti-rabbit (RRID:AB_143165) used after incubation of sections with rabbit anti-5-HT antibody (RRID: AB_1572725) (Gau et al., 2009). Bilateral microinjections of 8-OHDPAT $\mathrm{HBr}\left(1 \mathrm{nmol}\right.$ per $100 \mathrm{nl}$ ), a $5-\mathrm{HT}_{1 \mathrm{~A}}$ receptor agonist (Hamon et al., 1988) that binds preferentially to autoreceptors on 5-HT neurons (Middlemiss \& Fozard, 1983), were made into the intermediate B3 region (Ootsuka \& Blessing, 2006).

Bilateral microinjections of granisetron ( $250 \mathrm{pmol}$ per $100 \mathrm{nl}$ ), a selective $5-\mathrm{HT}_{3}$ receptor antagonist (Carmichael et al., 1989), were made into the commissural NTS at the level of the calamus scriptorius, at co-ordinates previously identified (i.e. $0.5 \mathrm{~mm}$ lateral and $0.5 \mathrm{~mm}$ ventral to the surface of the brain, Sévoz-Couche et al., 2013). 
Bilateral microinjections of saline for control were made into the intermediate B3 region and the NTS. Baroreflex control and experimental responses (15 $\mathrm{min}$ apart) were both elicited in the same rat before and 15 min after microinjections of saline or either bodipy muscimol or 8-OH-DPAT into the B3 region and saline or granisetron into the NTS. At the end of the experiments, animals were killed by administering an overdose of pentobarbitone $\left(200 \mathrm{mg} \cdot \mathrm{kg}^{-1}\right.$, i.p.).

\subsection{Histological localization of microinjection and stimulation sites}

Microinjection sites were identified by the location of the micropipette track and pontamine sky blue deposit in 70- $\mu$ m-thick sections of brain tissue previously fixed in $10 \%$ formalin solution and cryoprotected in $20 \%$ sucrose solution for 5 days.

\section{6 | Data and statistical analyses}

The data and statistical analysis comply with the recommendations of the British Journal of Pharmacology on experimental design and analysis in pharmacology (Curtis et al., 2018). Sample sizes subjected to statistical analysis was at least 6 animals per group $(n=6)$, where $n$ is the number of independent values. Parametric analyses were used as all data sets (raw or log-transformed) successfully passed the Shapiro-Wilk test for normality and Leven's test for equality of variance (Niérat et al., 2017). Student's unpaired $t$-test (GraphPad Prism 6) was used to compare Fos expression in 5-HT cells in control (saline) or experimental (rostral cuneiform disinhibtion) rats. Two-way repeated measures ANOVA (GraphPad Prism 6, San Diego, CA, USA) was used to compare the baroreflex range responses and BRS in control and experimental conditions, before and after local microinjections in $\mathrm{B} 3$ and NTS in rats or WT and $5-\mathrm{HT}_{3}$ receptor knockout mice. Bonferroni corrections were applied to all ANOVAs only if $F$ in ANOVA achieved $P<.05$, and differences were considered significant at $P<.05$.

\section{7 | Materials}

8-OH-DPAT, atenolol, bicuculline, muscimol, phenylephrine and sodium nitroprusside were supplied by Sigma Aldrich Chimie (Saint-Quentin-Fallavier, France). The bodipy TMR-X conjugate muscimol was supplied by Invitrogen (Ref M-23400; Pontoise, France).

\section{8 | Nomenclature of targets and ligands}

Key protein targets and ligands in this article are hyperlinked to corresponding entries in the IUPHAR/BPS Guide to PHARMACOLOGY http://www.guidetopharmacology.org and are permanently archived in the Concise Guide to PHARMACOLOGY 2019/20 (Alexander, Christopoulos, et al., 2019; Alexander, Mathie, et al., 2019).

\section{3 | RESULTS}

\section{1 | Functional interaction between the rostral cuneiform nucleus and raphé nuclei in rats}

\subsection{1 | Fos immunohistochemical labelling after vehicle (sham) or bicuculline (experimental) into the rostral cuneiform nucleus}

\section{B3 nuclei}

An increase in Fos-5-HT-IR cell number in the experimental condition compared to sham was confined to the mid-rostrocaudal extent of the B3 5-HT group, from -10.2 to $-11.8 \mathrm{~mm}$ from bregma (Paxinos \& Watson, 2005). Considering absolute values, that is, mean number of neurons per rat, the total number of $5-\mathrm{HT}$-IR cells was similar in sham and experimental animals in ipsilateral (130 \pm 10 vs. $120 \pm 8$ ) or contralateral (125 \pm 7 vs. $122 \pm 6) \mathrm{LPGi}$, as well as in the RMg $(280 \pm 5$ vs. $250 \pm 10$ ). Among total LPGi 5 -HT-IR cells, unilateral rostral cuneiform disinhibition (experimental conditions) induced an increase in Fos expression by more than 20-fold in each side compared to sham (Figure 1a). A representative example in ipsilateral LPGi is given in Figure $1 \mathrm{~b}$. The number of double-labelled cells in RMg was also significantly higher in experimental than in sham conditions, though the increase (10-fold) was slightly less than in total LPGi (Figure 1a).

Non-5-HT-IR neurons expressing Fos slightly increased in experimental compared to sham conditions in total LPGi, as well as in $\mathrm{RMg}$

\section{Raphé dorsalis (RDr)}

The RDr extends from -7.0 to $-8.5 \mathrm{~mm}$ from bregma. In this region, the total number of 5-HT-IR cells was similar in sham and experimental animals (2,550 \pm 110 vs. $2,420 \pm 130$, Figure 2a). We only observed a slight tendency to increase of 5-HT-IR cells expressing Fos in experimental compared to sham conditions (Figure 1a). In contrast, bicuculline given into the rostral cuneiform nucleus (experimental) induced a large increase in Fos-IR cells in the non-5-HT-IR population compared to sham (Figure 2a), especially in lateral wings at mid-rostrocaudal levels $(-7.5$ to $8.0 \mathrm{~mm}$ from bregma). A representative example in the experimental condition is given in Figure $2 b$.

\section{$R P a$ and $R O b$}

Analyses were performed between -10.0 and $-13.0 \mathrm{~mm}$ from bregma. The total number of 5-HT-IR cells was similar in sham and experimental animals in RPa $(27 \pm 2$ vs. $22 \pm 3)$ or ROb $(153 \pm 8$ vs. $138 \pm 6$ ). $5-\mathrm{HT}-\mathrm{IR}$ cells expressing Fos in these two regions were not affected by rostral cuneiform disinhibition compared 


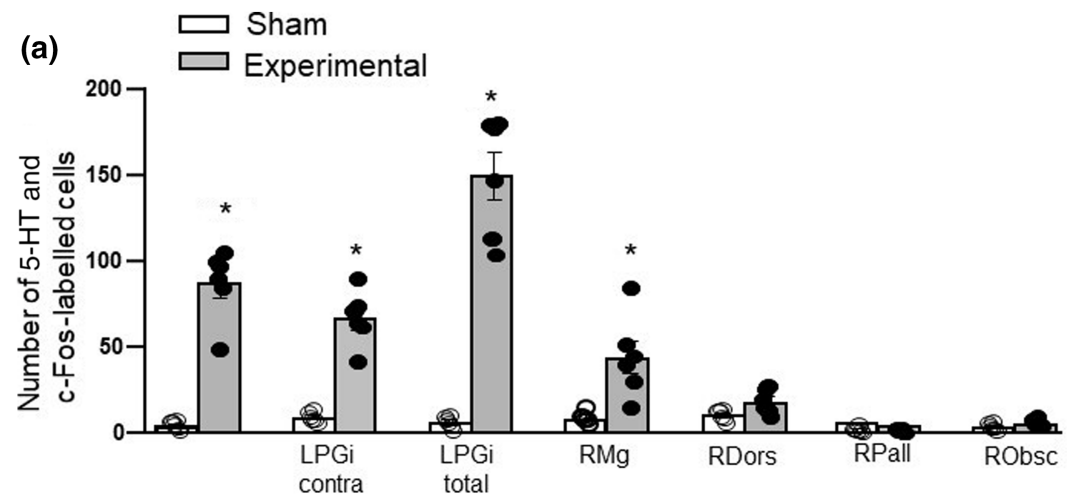

(b)

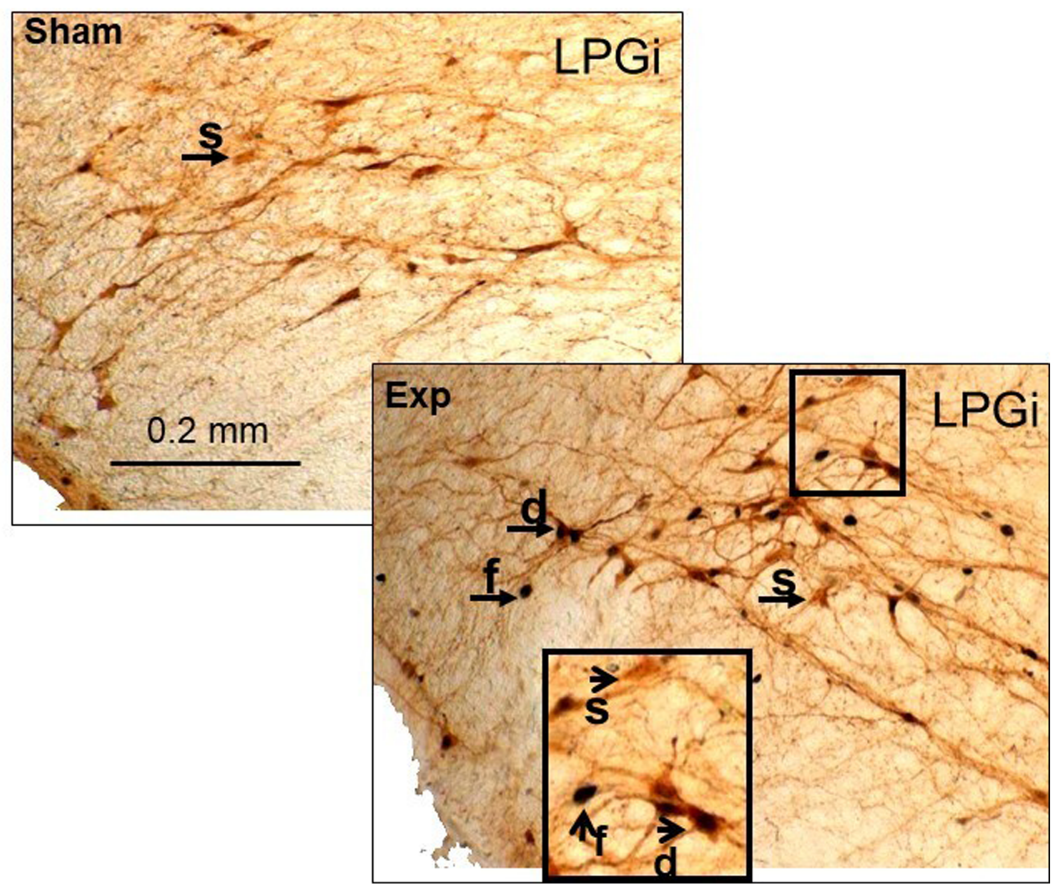

FIGURE 1 Increase in Fos expression in 5-HT neurons after rostral CnF stimulation. (a) Bar graphs with individual values showing an increased number of 5 -HT cells (in four brain sections) expressing Fos protein immunoreactivity in ipsilateral (ipsi) as well as contralateral (contra) lateral paragigantocellular nucleus (LPGi), total LPGi and raphe magnus (RMg), but not in raphe dorsalis (RDors), raphe pallidus (RPall),and raphe obscurus (RObsc), in experimental (intra-cuneiform bicuculline, filled bars) compared to sham (intra-cuneiform saline, open bars) conditions. Each bar is the mean \pm SEM. ${ }^{*} P<.05$, significantly different from sham. (b) Photomicrographs of the LPGi at approximately $-11.2 \mathrm{~mm}$ from bregma in sham and experimental condition. The high magnification microphotograph is the region framed in the contralateral LPGi of the experimental condition. Arrows with $\mathrm{d}, \mathrm{s}$ and $\mathrm{f}$ indicate examples of Fos + 5-HT double-labelled (black core surrounded by brown staining), 5-HT single-labelled (cytoplasm brown staining) and Fos single-labelled (nucleus black staining) neurons respectively to sham (Figure 1a). No increase in Fos expression was seen in the non-5-HT-IR population in the $\mathrm{RPa}$ or $\mathrm{ROb}$ after bicuculline into the rostral cuneiformis nucleus compared to sham (Figure 2a).

\subsubsection{Anatomical link between the rostral cuneiform nucleus and B3}

The anterograde tracer was unilaterally applied in the rostral cuneiform nucleus (Figure 3a). Labelled fine fibres and ramifications with numerous varicosities were highly concentrated in the middle B3 (Figure $3 b$ ). The maximum density of labelled fibres was found in the intermediate B3 region, between -10.4 to $-11.6 \mathrm{~mm}$ from bregma (Paxinos \& Watson, 2005). The majority of the labelled fibres were found bilaterally in the LPGi and only a few labelled fibres were observed in the RMg (Figure 3c).

\subsection{Inhibitory effects of rostral cuneiform:} disinhibition on the baroreflex cardiac response in rats and mice

\subsection{1 | Involvement of the intermediate 5-HT B3 region: effects of muscimol and 8-OH-DPAT on baroreflex cardiac response induced by rostral cuneiform disinhibition in rats}

The results in Figure $1 \mathrm{~b}$ show that the microinjections of muscimol and 8-OH-DPAT were performed at intermediate B3 coordinates (Figure 4a). The baroreflex response was carried out in the same rat alone (control condition) or during (experimental condition) rostral cuneiform disinhibition, before and after intra-B3 treatment. Interaction between conditions and intra-B3 muscimol or 8-OH-DPAT but not saline was seen over the maximal cardiac range (Table 1 ) and rectilinear slopes (BRS) derived from baroreflex sigmoid curves (Table 2). 
FIGURE 2 Increase in Fos expression in non5-HT neurons after rostral cuneiform stimulation. (a) Bar graphs with individual values showing an increased number of non-5-HT cells expressing Fos protein immunoreactivity in total LPGi, RMg and RDors, but not in RPall and RObs, in experimental compared to sham conditions. Each bar is the mean \pm SEM. ${ }^{*} P<.05$, significantly different from sham.. Abbreviations as in Figure 1. (b) Photomicrographs of the raphe dorsalis in sham and experimental (Exp) condition. The high magnification microphotograph is the raphe dorsalis region framed in the experimental condition. Aq, aqueduct; dIPAG, dorsolateral column of the periaqueductal grey area; dPAG, dorsal column of the periaqueductal grey area; IPAG, lateral column of the periaqueductal grey area; RDors, raphé dorsalis; vPAG, ventrolateral column of the periaqueductal grey area

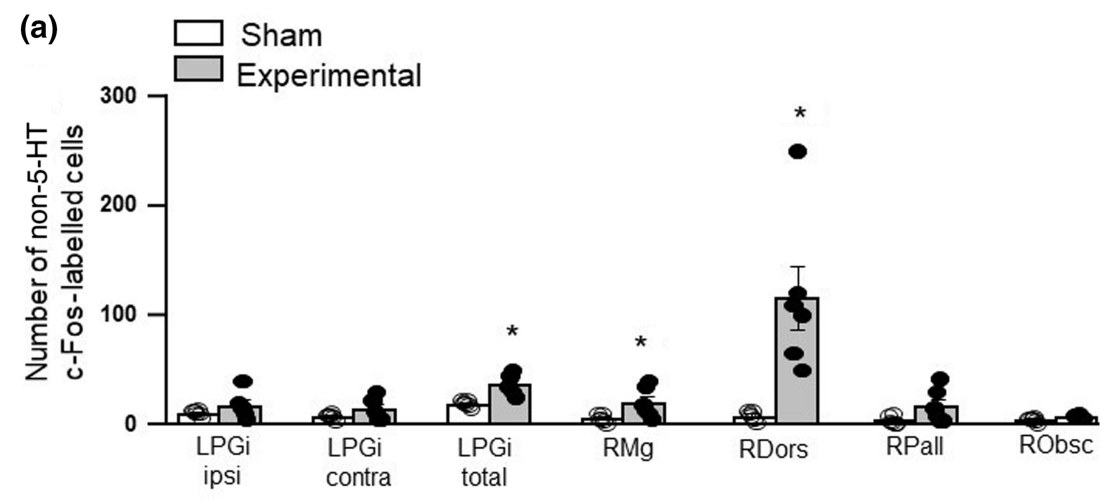

(b)

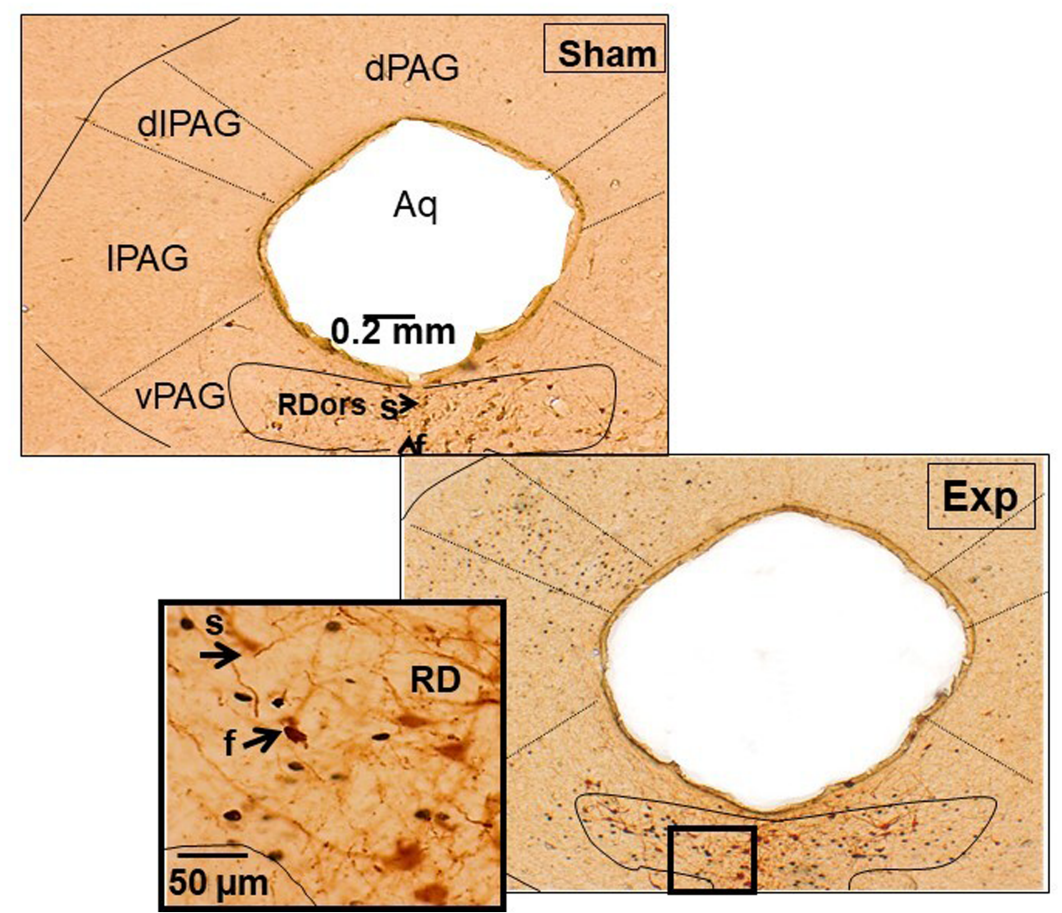

An example of injections of muscimol conjugated to bodipy into B3 targeting the LPGi or the RMg is given in Figure 4b-1,b2 respectively. We pooled our results as no difference between LPGi and $\mathrm{RMg}$ microinjections were observed. A representative example of control and experimental baroreflex responses obtained before and after intra-B3 muscimol injection is given in Figure 5a-1. The maximal baroreflex cardiac range obtained from sigmoid curves (Figure 5a-2) was significantly reduced in experimental conditions before $(75 \pm 1 \mathrm{bpm})$ but not after (145 $\pm 3 \mathrm{bpm})$ intra-B3 treatment, compared with control conditions $(165 \pm 3$ and $155 \pm 6 \mathrm{bpm}$, respectively) (Figure S1). In the same manner, experimental BRS derived from the sigmoid curves was lower before $\left(2.1 \pm 0.1 \mathrm{bpm} \cdot \mathrm{mmHg}^{-1}\right)$ but not after $\left(5.1 \pm 0.2 \mathrm{bpm} \cdot \mathrm{mmHg}^{-1}\right)$ intra-B3 muscimol than control BRS $(6.4 \pm 0.1$ and $6.2 \pm 0.1 \mathrm{bpm} \cdot \mathrm{mmHg}^{-1}$, respectively) (Figure S1).

The maximal baroreflex cardiac range obtained from sigmoid curves (Figure 5b) was significantly reduced in experimental conditions before (59 $\pm 4 \mathrm{bpm}$ ) but not after (130 $\pm 7 \mathrm{bpm}$ ) intra-B3 8-OH-DPAT compared with control conditions $(160 \pm 3$ and $147 \pm 4 \mathrm{bpm}$, respectively) (Figure S1). In the same manner, experimental BRS was lower before $\left(1.10 \pm 0.05 \mathrm{bpm} \cdot \mathrm{mmHg}^{-1}\right)$ but not after $\left(5.53 \pm 0.09 \mathrm{bpm} \cdot \mathrm{mmHg}^{-1}\right)$ intra-B3 8-OH-DPAT than control BRS (5.91 \pm 0.07 and $6.21 \pm 0.19 \mathrm{bpm} \cdot \mathrm{mmHg}^{-1}$, respectively) (Figure S1).

Experimental cardiac baroreflex ranges from the baroreflex sigmoid curves before and after intra-B3 saline (52 \pm 4 and $54 \pm 4$ bpm, respectively) were both lower than in controls (156 \pm 3 and $163 \pm 3$ bpm, respectively). Similarly, experimental BRS was lower from control BRS before (1.3 \pm 0.1 vs. $\left.5.6 \pm 0.1 \mathrm{bpm} \cdot \mathrm{mmHg}^{-1}\right)$ and after $\left(1.4 \pm 0.1\right.$ vs. $\left.5.7 \pm 0.1 \mathrm{bpm} \cdot \mathrm{mmHg}^{-1}\right)$ intra-B3 saline (Figure S2).

\subsection{2 | Involvement of $5-\mathrm{HT}_{3}$ receptors}

\section{Effects of granisetron on baroreflex cardiac response inhibition induced by rostral cuneiform disinhibition in rats}

The baroreflex response was performed in the same rat before (control condition) and during (experimental condition) intracuneiform bicuculline, before and after intra-NTS injection. 
(a)

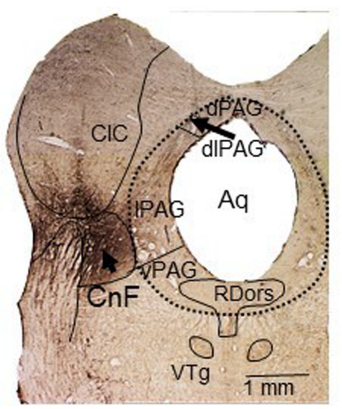

(b)

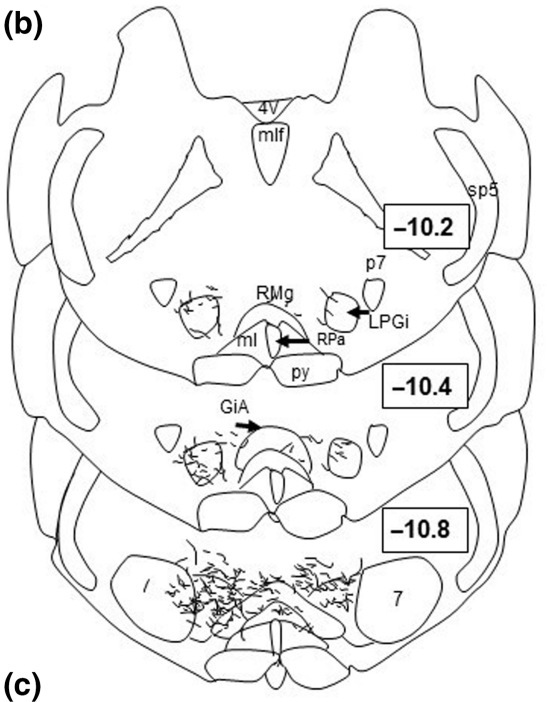

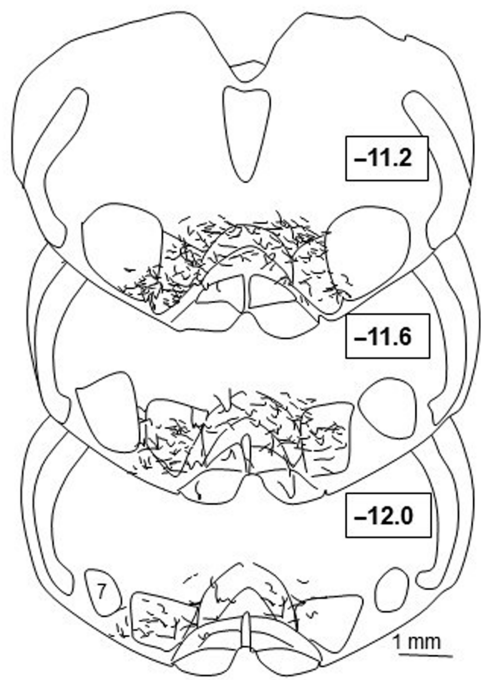

FIGURE 3 Projections from the rostral cuneiform nucleus to the B3 region.

(a) Photomicrograph displaying the site of Phaseolus vulgaris leucoagglutinin lectin (PHA-L) unilateral injection in the rostral cuneiform nucleus ( $\mathrm{CnF}$, arrow), at approximately $8.2 \mathrm{~mm}$ caudal to bregma. (b) Camera lucida drawings of anterograde labelling of descending axons and terminal boutons in $B 3$ from injection of PHA-L in the rostral cuneiform nucleus seen in (a). Series of transverse sections. Numbers indicate the distance (in $\mathrm{mm}$ ) from bregma.

(c) Photomicrographs corresponding to approximately $-11.4 \mathrm{~mm}$ from bregma. PHA-L-immunolabelled fibres and varicosities in the LPGi are shown in framed $\times 20$ magnification photomicrograph. 7, facial motor nucleus; CIC, central nucleus of the inferior colliculus; GiA, gigantocellular reticular nucleus alpha; $\mathrm{ml}$, medial lemniscus; p7, perifacial zone; py, pyramidal tract; sp5, spinal trigeminal tract; VTg, ventral tegmentum. Other abbreviations as in Figures 1 and 2

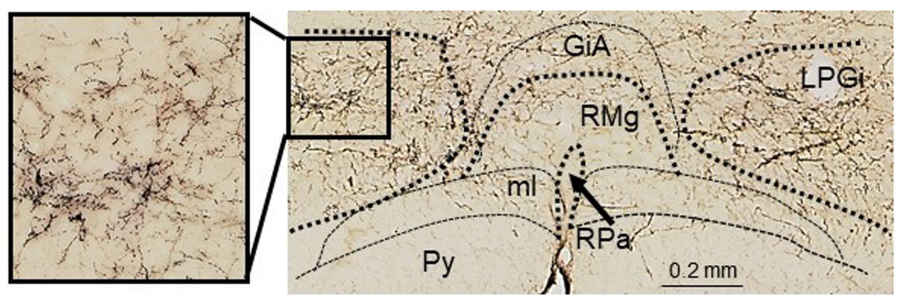

Interaction between conditions and intra-NTS granisetron but not saline was seen for maximal baroreflex range (Table 1) and BRS (Table 2). The maximal cardiac range obtained from the baroreflex sigmoid curves (Figure 5c) in experimental conditions was significantly reduced before (38 $\pm 3 \mathrm{bpm}$ ) but not after (130 $\pm 5 \mathrm{bpm})$ intra-NTS granisetron, compared with control conditions (160 \pm 5 and $141 \pm 4$ bpm, respectively) (Figure S1). In the same manner, the experimental BRS derived from the sigmoid curves was lower before $\left(1.4 \pm 0.2 \mathrm{bpm} \cdot \mathrm{mmHg}^{-1}\right)$ but not after $\left(5.4 \pm 0.1 \mathrm{bpm} \cdot \mathrm{mmHg}^{-1}\right)$ granisetron than control BRS $\left(5.9 \pm 0.1\right.$ and $6.0 \pm 0.1 \mathrm{bpm} \cdot \mathrm{mmHg}^{-1}$, respectively) (Figure S1).

Experimental cardiac baroreflex ranges from the baroreflex sigmoid curves before and after intra-NTS saline (56 \pm 3 and $53 \pm 3 \mathrm{bpm}$, respectively) were both lower than in control conditions (163 \pm 3 and $157 \pm 4 \mathrm{bpm}$, respectively). Similarly, experimental BRS was lower than control before $\left(1.4 \pm 0.1\right.$ vs. $\left.5.7 \pm 0.1 \mathrm{bpm} \cdot \mathrm{mmHg}^{-1}\right)$ and after $\left(1.4 \pm 0.1\right.$ vs. $\left.5.8 \pm 0.1 \mathrm{bpm} \cdot \mathrm{mmHg}^{-1}\right)$ intra-NTS saline (Figure S2).
Involvement of 5- $\mathrm{HT}_{3}$ receptors in mice: effects of rostral cuneiform disinhibition on baroreflex cardiac response in WT and $5-\mathrm{HT}_{3}$ receptor knockout mice

Injections of bicuculline into the rostral cuneiform were performed in WT or $5-\mathrm{HT}_{3}$ receptor knockout mice (Figure 6a). An example of injection at $4.6 \mathrm{~mm}$ from bregma is given in Figure $6 \mathrm{~b}$. The baroreflex response was performed in the same animal before (control condition) and during (experimental condition), either in WT or in $5-\mathrm{HT}_{3}$ receptor knockout mice. A representative example is given in Figure 7a.

Interaction between condition and mice genotype was seen for maximal baroreflex range (Table 1) and BRS (Table 2). The maximal cardiac range obtained from the baroreflex sigmoid curves in experimental conditions was significantly reduced in WT (125 \pm 5 bpm) but not in knockout (243 $\pm 7 \mathrm{bpm}$ ) mice (Figure $7 \mathrm{~b}$ ), compared with control conditions (231 \pm 7 and $243 \pm 5 \mathrm{bpm}$ ) (Figure S1). In the same manner, experimental BRS derived from the sigmoid curves was lower in WT $\left(3.3 \pm 0.3 \mathrm{bpm} \cdot \mathrm{mmHg}^{-1}\right)$ but not in knockout 
FIGURE 4 Microinjection sites of muscimol into the B3 group in rats. (a) Coronal sections at the level of B3 group showing bilateral microinjections of bodipy muscimol (black circle), 8-OH-DPAT (grey circle), or saline (white circle). Abbreviations as in Figure 3. (b) Reconstructive photomicrograph showing the bilateral microinjection of bodipy muscimol (orange fluorescence) within the 5-HT neuron area (green cells) of LPGi (b-1) and RMg (b-2) shown by arrows in (a) at -11.2 and $-11.4 \mathrm{~mm}$ from bregma, respectively (a)

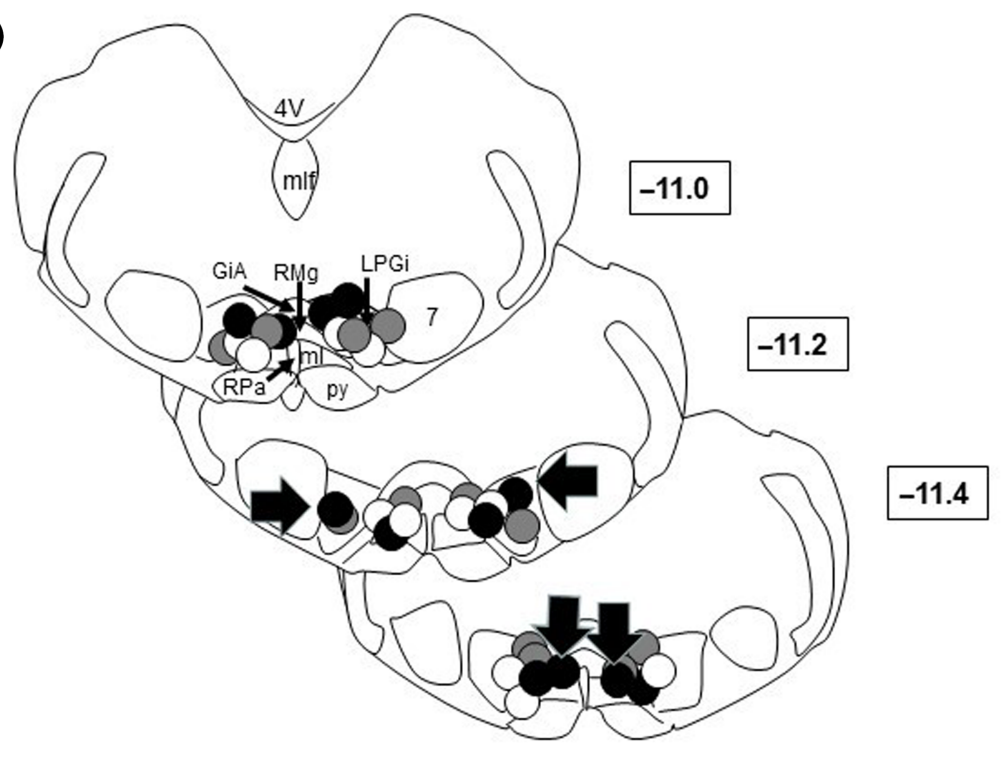

(b-1)

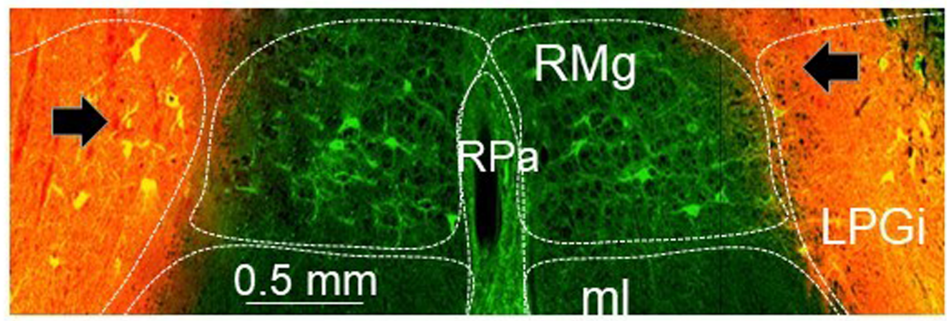

(b-2)

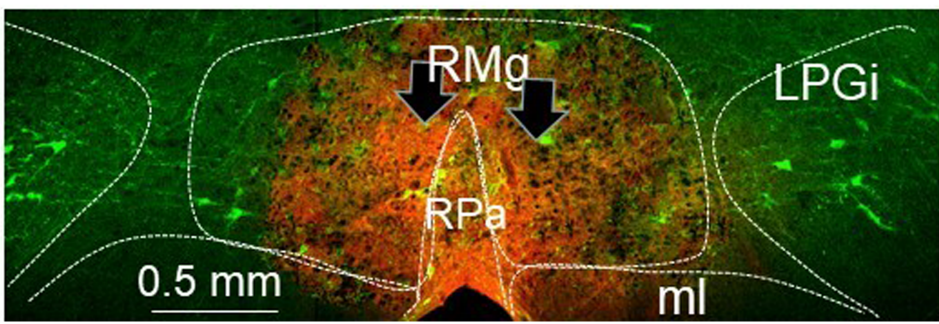

$\left(7.9 \pm 0.1 \mathrm{bpm} \cdot \mathrm{mmHg}^{-1}\right)$ mice than control BRS $(8.3 \pm 0.3$ and $8.0 \pm 0.1 \mathrm{bpm} \cdot \mathrm{mmHg}^{-1}$, respectively) (Figure S1).

\section{DISCUSSION}

This study confirms and extends previous observations on the baroreflex inhibition during rostral cuneiform disinhibition. This negative control involves both LPGi and RMg in the intermediate B3, but direct links were found to reach only LPGi. 5-HT-IR cells in B3 are the source of the 5-HT released into the NTS to activate $5-\mathrm{HT}_{3}$ receptors and block second-order baroreceptor neurons.

\subsection{Fos expression in raphé nuclei}

The defence reaction is associated with an inhibition of the baroreflex response (Nosaka, 1996). We showed in different studies that this effect involved the activation of NTS $5-\mathrm{HT}_{3}$ receptors (Bernard et al., 2008; Comet et al., 2004, 2005; Sévoz-Couche et al., 2003). The NTS receives 5 -HT projections from various raphé nuclei, including the RPa and the ROb (Palkovits et al., 1986), as well as the RDr (Schaffar et al., 1988) and, in B3, the RMg (Schaffar et al., 1988; Thor \& Helke, 1987) and the LPGi (Babic \& Ciriello, 2004; Schaffar et al., 1988). Therefore, these raphé nuclei are potential candidates to be involved in NTS $5-\mathrm{HT}_{3}$ receptor activation during the defence reaction. We showed that activation of the dorsolateral PAG, a key 
TAB LE 1 Statistical analysis of the interaction between the condition and intracerebral microinjections or mice genotyping, on the maximal baroreflex range using two-way repeated measures ANOVA

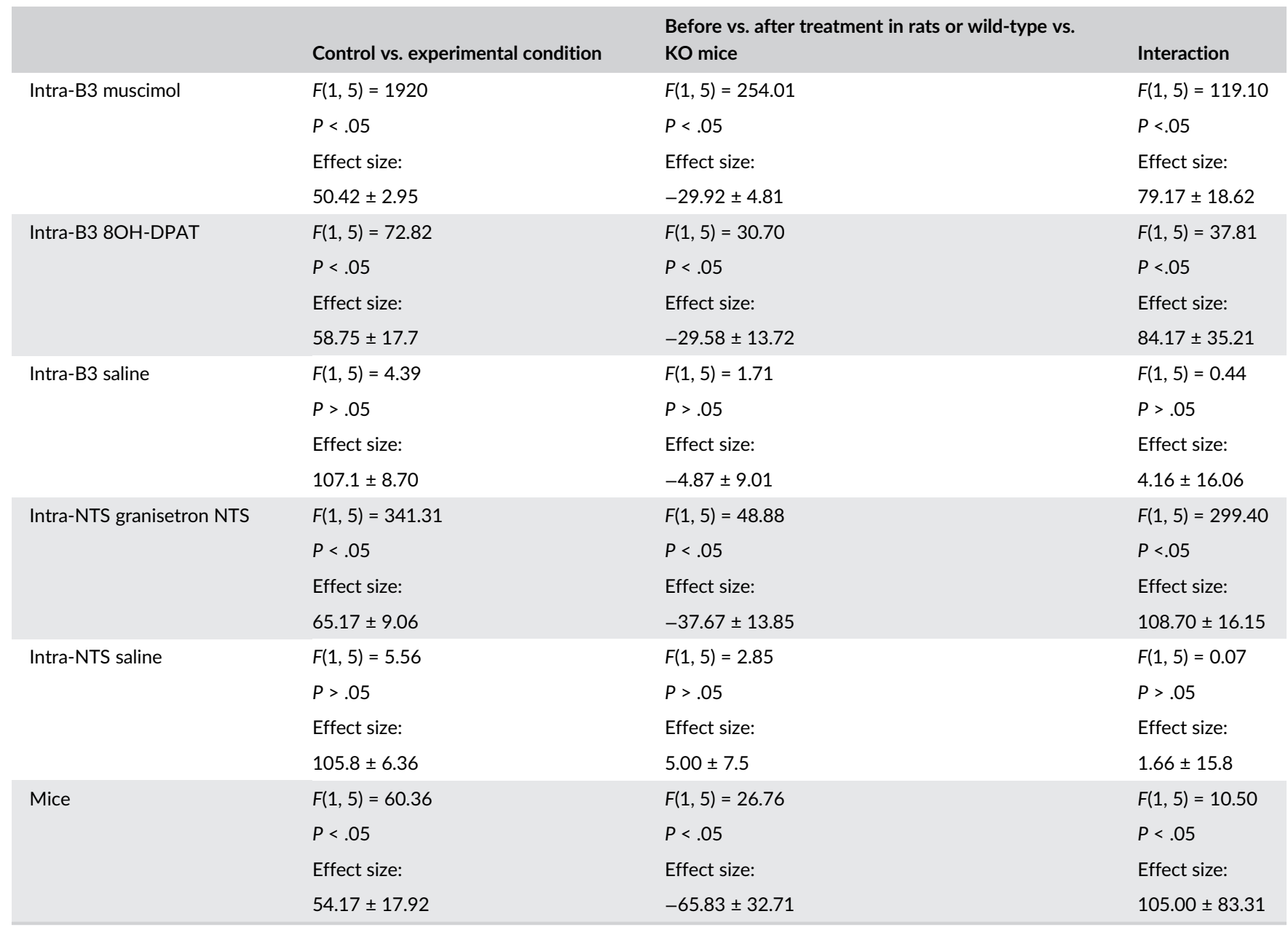

Note: "Effect size" indicates the difference between means $\pm 95 \%$ confidence interval of difference.

area of the defence reaction, induced a baroreflex inhibition through intermediate B3 raphé nuclei only (Bernard et al., 2008). Upstream to the dorsolateral PAG, disinhibition of local cells at specific coordinates (between -8.0 and $-8.4 \mathrm{~mm}$ from bregma) in the rostral cuneiform nucleus following bicuculline microinjections induced tachypnoea, tachycardia and hypertension associated with the inhibition of the baroreflex response (Netzer et al., 2011). We first examined whether B3 but also other raphé nuclei were activated during left rostral cuneiform disinhibition. As found for dorsolateral PAG activation (Bernard et al., 2008) only raphé nuclei in the intermediate B3 exhibited bilateral double-labelled Fos-5-HT cells following left rostral cuneiform disinhibition, with a higher proportion found in the LPGi than in the RMg. It is unlikely that this result in B3 was a consequence of indirect feedback evoked from the resulting increases in BP and HR. Indeed, no increase of Fos expression was described in the $\mathrm{B} 3$ region in response to $\mathrm{BP}$ changes (Dampney \& Horiuchi, 2003). No changes were observed in other parts of the 5-HT system, including the RDr. These results differ from those found with social stress. Indeed, a single exposure to social defeat has been found to selectively activate $5-\mathrm{HT}$ neurons in the mid-rostrocaudal and caudal dorsal raphé nucleus (Gardner et al., 2005; Lkhagvasuren et al., 2014). Similarly, chronic emotional stress (maternal separation or chronic mild stress, Pollano et al., 2018) increases the number of Fos-5-HT immunoreactive cells in the dorsolateral and ventrolateral part of the RDr. Therefore, at least concerning activation of 5-HT neurons in the RDr, the mechanisms involved in defence reaction (here, related to panic attack; Johnson et al., 2008) and social emotional stress (closer from anxiety and/or depression; Blugeot et al., 2011; Sévoz-Couche et al., 2013) seem different.

Rostral cuneiform disinhibition also produced Fos expression in non-5-HT neurons in B3. The RMg and LPGi contain non-5-HT neurons that may be ON and OFF cells responding to noxious tail heat (Gao \& Mason, 2000). These cell types have been proposed to play an important role in modulating the alertness evoked by any brief external stimulus, either noxious or innocuous. ON cells may facilitate alertness during waking and OFF cells suppress arousals during sleep (Foo \& Mason, 2003). Therefore, activation of non-5-HT-IR neurons in $\mathrm{B} 3$ induced by cuneiform disinhibition may participate in increased alertness during the defence reaction. 
TAB LE 2 Statistical analysis of the interaction between the condition and intracerebral microinjections or mice genotyping, on the baroreflex rectilinear slope (BRS) using two-way repeated measures ANOVA

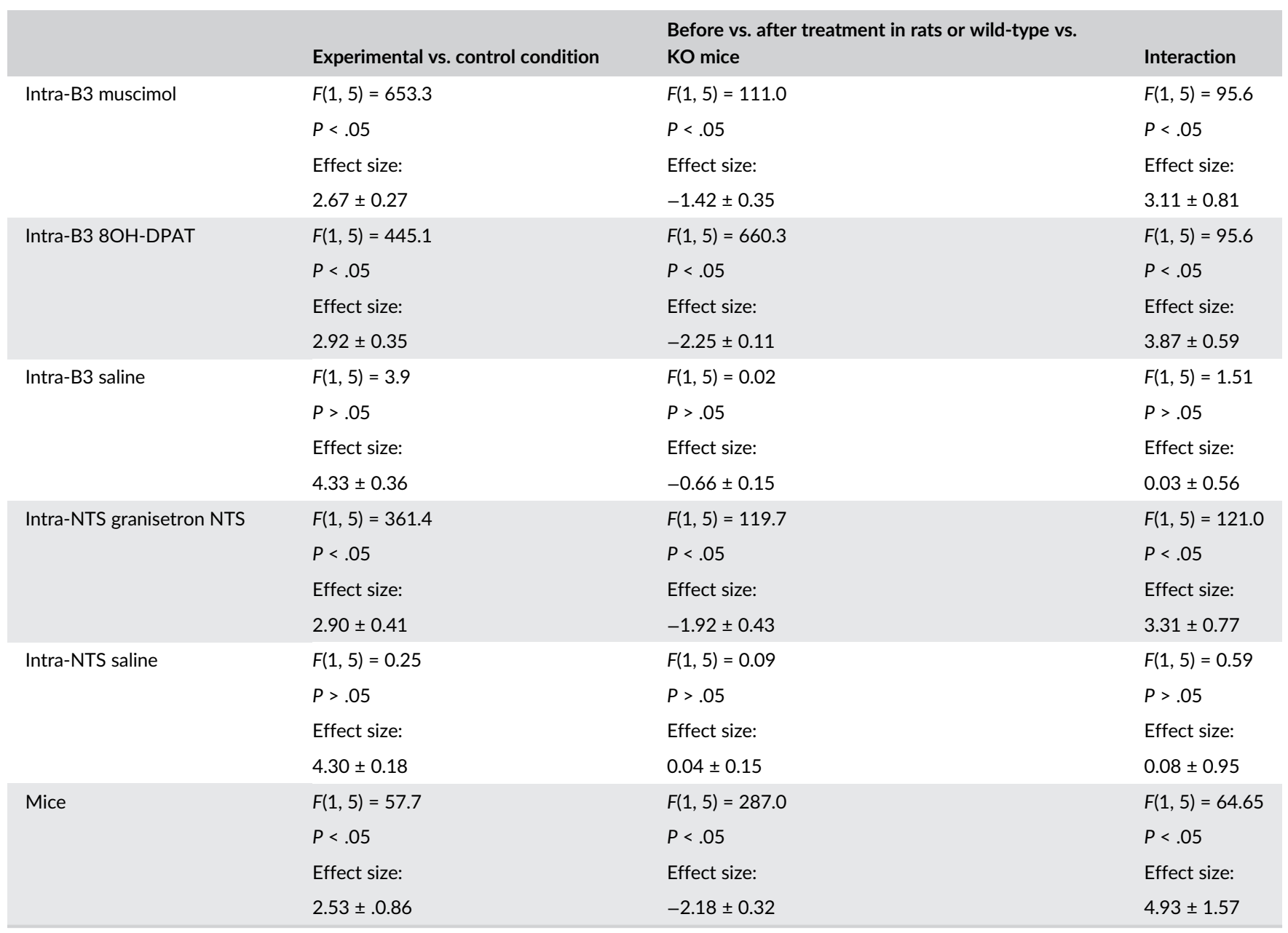

Note: "Effect size" indicates the difference between means $\pm 95 \%$ confidence interval of difference.

Interestingly, non-5-HT-Fos-IR cells have also been found in the caudal part of the RDr, especially in the mid-rostrocaudal lateral divisions of the nucleus. To note, active escape expression in the elevated T-maze recruited non-5-HT neurons within the lateral wings of the RDr (Spiacci et al., 2012) and systemic injection of sodium lactate in a group of pharmacologically induced panic-prone rats was accompanied by the expression of a greater number of Fos-immunopositive non-5-HT neurons preponderantly within the lateral mid-rostro-caudal RDr (Johnson et al., 2008), similar to that between defence reaction and panic attack we mentioned above. Activation of RDr non-5-HT neurons during cuneiform disinhibition or panic expression may be involved in descending analgesia because a double fluorescence immunohistochemistry study revealed that RDr neurons expressing Fos after picrotoxin administration were non-5-HT neurons (Koyama et al., 2000).

\subsection{Anterograde tracing from the rostral cuneiform nucleus to the intermediate B3}

The rostral cuneiform nucleus targets the dorsolateral PAG (Netzer et al., 2011) and the dorsolateral PAG sends projections to the intermediate B3 region, at the level of the LPGi (Babic \& Ciriello, 2004; Cameron et al., 1995). Previous reports using different retrograde tracers including HRP and colloidal gold-labelled wheat germ agglutinin conjugated to HRP showed that neurons labelled from the RMg are distributed throughout the dorsal, lateral and ventrolateral PAG, but not the dorsolateral column (Abols \& Basbaum, 1981; Babic \& Ciriello, 2004; Yin et al., 2014). In the same manner, using anterograde tracing from the left rostral cuneiform nucleus, we show here that extensive projections reach the LPGi, at the area (intermediate level of B3) in which we identified Fos-5-HT-IR cells in the first set of experiments. In addition, as these projections were seen bilaterally, these data explain why disinhibition performed on one side can induce bilateral LPGi activation. However, only scarce labelling from the rostral cuneiform nucleus to the RMg was observed in the present study, though projections exist from the pre-cuneiform nucleus to the caudal RMg (Abols \& Basbaum, 1981; Carlton et al., 1983; Zemlan \& Behbehani, 1988). Therefore, the origin of RMg $5-\mathrm{HT}$ cell activation after cuneiform disinhibition (and dorsolateral PAG activation) remains unclear. One possibility could be that rostral cuneiform disinhibition partly activates the dorsal and/or lateral PAG along with dorsolateral PAG, even if there was very little Fos expression was observed here 
(a-1) Before intra-B3 muscimol

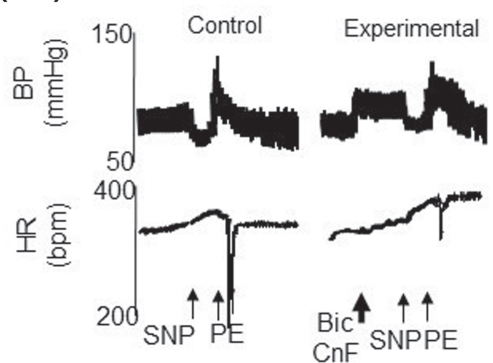

(a-2)

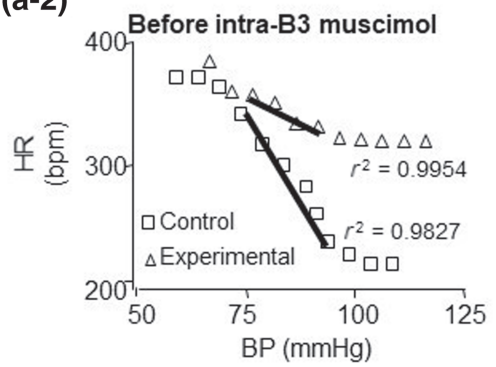

(b)

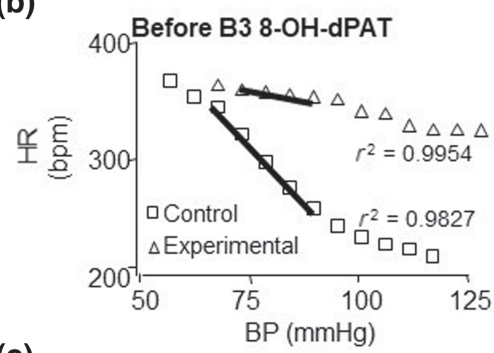

(c)

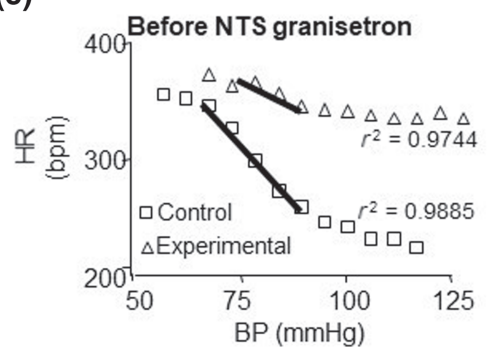

After intra-B3 muscimol
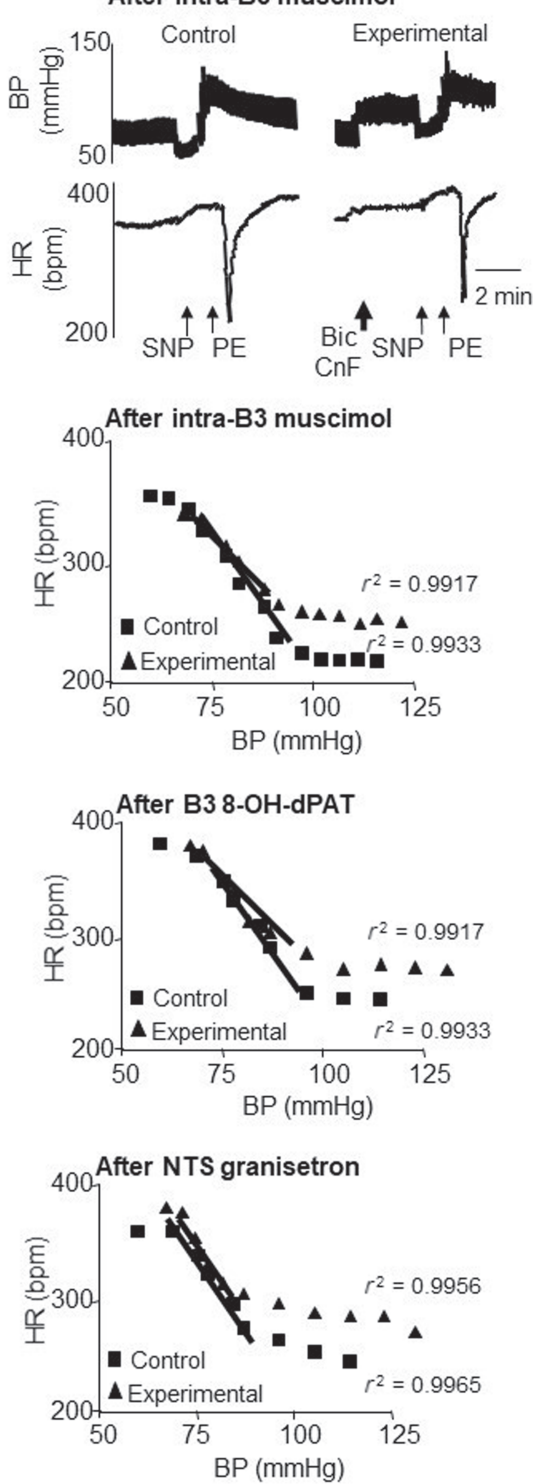

FIGURE 5 Inhibition of the baroreflex curves after disinhibition of the rostral cuneiform nucleus in rats. (a-1) Representative recordings illustrating that pharmacological disinhibition of the rostral cuneiform nucleus by local application of bicuculline (Bic $\mathrm{CnF}$, experimental) did not affect the baroreflex tachycardia induced by administration of the vasodilator nitroprusside (SNP) but inhibited the reflex bradycardia induced by administration of the vasoconstrictor phenylephrine $(\mathrm{PE})$ compared to the control condition, before but not after intra-B3 muscimol. (a-2) Sigmoid baroreflex curves corresponding to the animal shown in (a-1) showing that the baroreflex cardiac response to MBP changes was reduced in experimental compared to control conditions, before but not after intra-B3 muscimol. (b, c) Sigmoid baroreflex curves showing that the baroreflex cardiac response to MBP changes was reduced in experimental compared to control conditions, before but not after intra-B3 8-OH-DPAT (b) or intra-NTS granisetron (c) and in previous study (Netzer et al., 2011). Another possibility is that the LPGi or the gigantocellular nucleus pars alpha (shown to receive numerous projections from the dorsolateral PAG, Cameron et al., 1995; rostral cuneiform nucleus [present study]) can activated downstream 5-HT neurons in the RMg following either rostral cuneiform disinhibition or dorsolateral PAG activation. In support of this possibility, both regions are known to send projections to the RMg (Hermann et al., 1997; Zagon, 1993).

\section{3 | Pharmacological experiments}

Like pentobarbitone (Sévoz-Couche et al., 2013), urethane anaesthetic was mainly used in our previous studies to successfully evaluate the baroreflex cardiac response during the defence reaction (Bernard et al., 2008; Comet et al., 2005; Sévoz-Couche et al., 2003). A less cardiovascular depressing anaesthetic, that is, an anaesthetic like isoflurane, could have been used, but that would not have been the same experimental conditions as in Netzer et al. (2011).

The chemical inhibition, by local administration of muscimol, of the intermediate B3 region (including both the LPGi and RMg) reduced the baroreflex inhibition induced by dorsolateral PAG activation (Bernard et al., 2008). We investigated in the present study the possibility that the $\mathrm{B} 3$ region could be at least in part the origin of the cuneiform-induced vagal baroreflex inhibition. It should be noted that atenolol was used in all experiments to eliminate the possible influence of the sympathetic mediated tachycardic response evoked by the defence reaction on the baroreflex (see Section 2). Atenolol would also prevent the sympathetic component of the baroreflex under normal physiological conditions (Head \& McCarty, 1987; Saad et al., 1989), although, we have shown that the defence reaction has no effect on the sympathetic baroreflex (Sévoz-Couche et al., 2003). 
FIGURE 6 Microinjection sites of bicuculline into the rostral cuneiform nucleus in mice.

(a) Coronal sections at the level of the rostral $\mathrm{CnF}$ showing unilateral microinjections of bicuculline in wild-type (grey circle) or $5-\mathrm{HT}_{3}$ knockout (black circle) mice.

(b) Photomicrograph showing pontamine blue deposit (arrow) below the tip of the micropipette used to inject bicuculline into the $\mathrm{CnF}$ at $-4.6 \mathrm{~mm}$ from bregma, as indicated by the arrow in (a). Abbreviations as in Figure 3 (a)

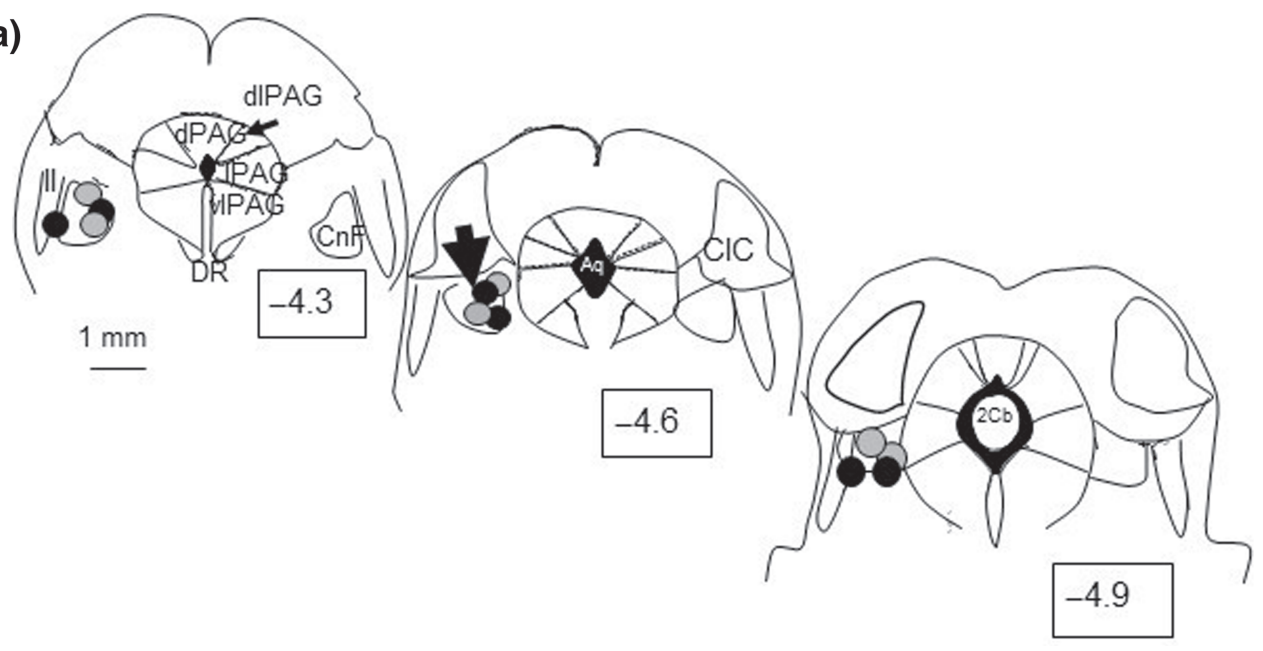

(b)

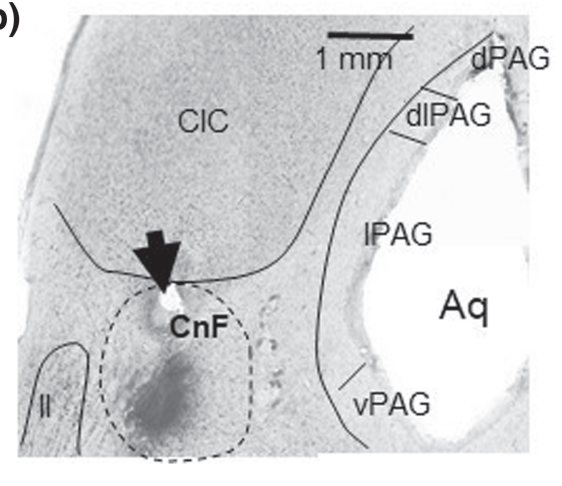

FIGURE 7 Inhibition of the baroreflex bradycardia after disinhibition of the rostral cuneiform nucleus in mice. (a) Representative recordings illustrating that pharmacological disinhibition of the rostral cuneiform nucleus by local application of bicuculline (Bic $\mathrm{CnF}$, experimental) did not affect the baroreflex tachycardia induced by administration of the vasodilator nitroprusside (SNP) but inhibited the reflex bradycardia induced by administration of the vasoconstrictor phenylephrine (PE) compared to the control condition, in wild-type but not in $5-\mathrm{HT}_{3}$ knockout mice. (b) Sigmoid baroreflex curves corresponding to the animal shown in

(a) showing that the decrease in $\mathrm{HR}$ in response to MBP changes was reduced in experimental compared to control conditions, in wild-type but not in $5-\mathrm{HT}_{3}$ knockout mice (a)

Wild-type
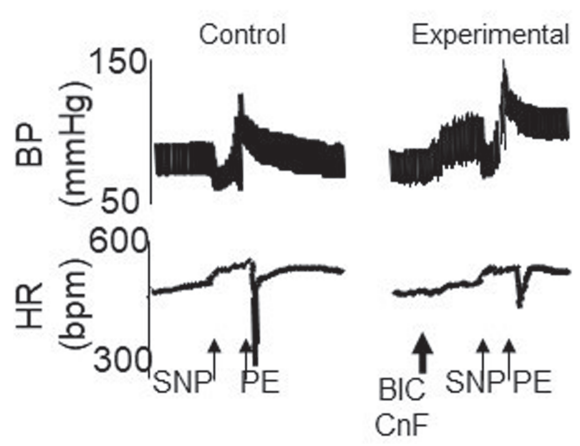

(b)

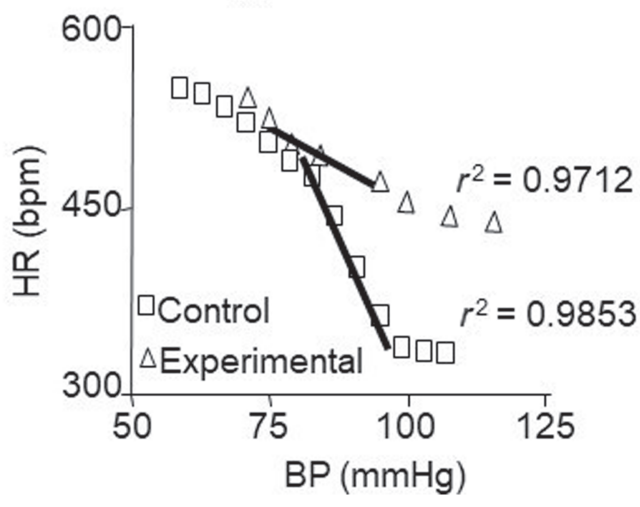

\section{5-HT 3 knockout}

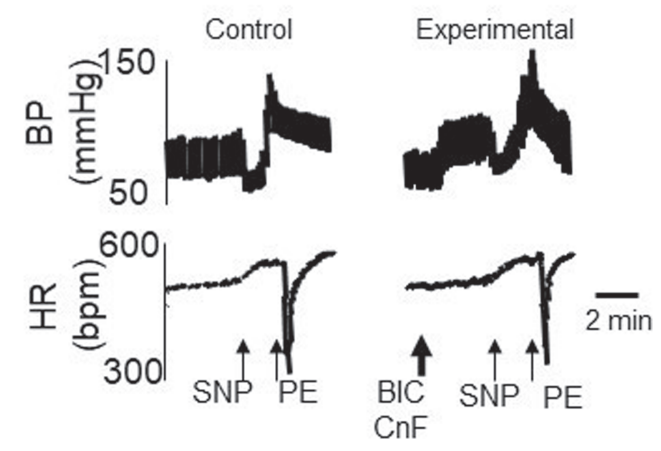

5-HT 3 knockout

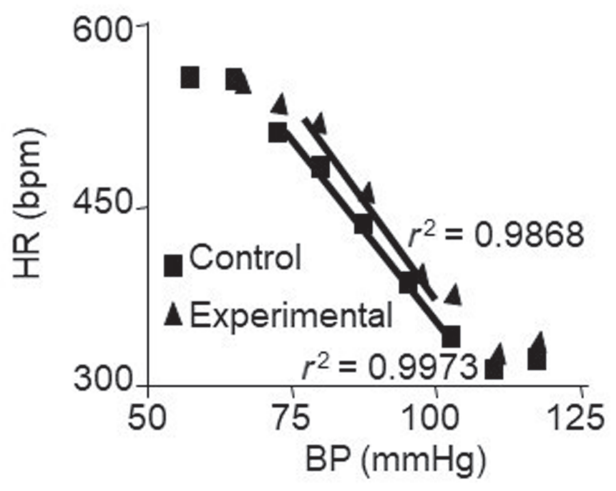




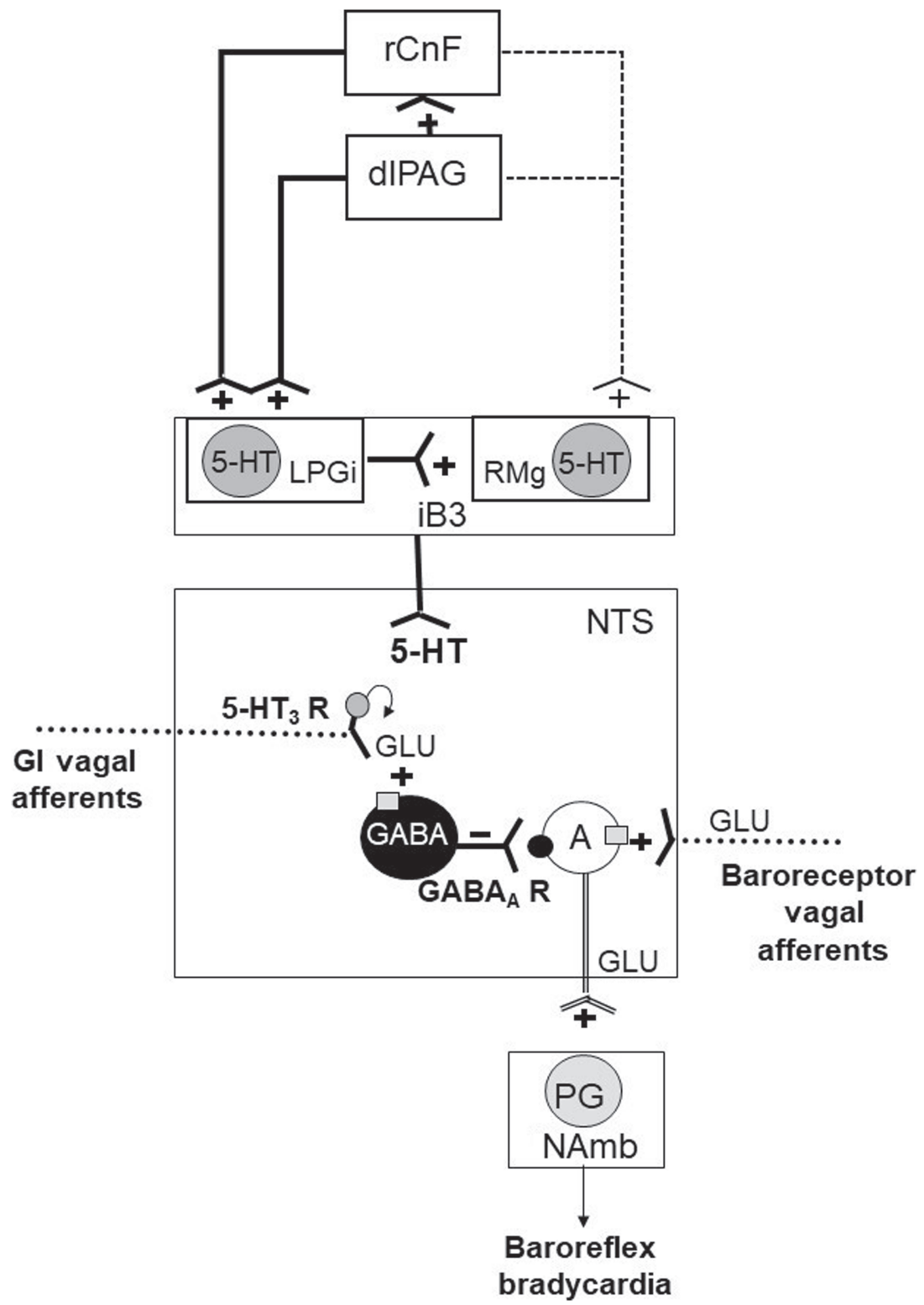

FIGURE 8 Schematic representation of putative medullary pathways producing baroreflex inhibition during the defence reaction.

Baroreceptor glutamatergic vagal afferents are known to excite barosensitive NTS cells

(A) through the glutamatergic (GLU) activation of metabotropic amino acid receptors (grey square) to induce vagal baroreceptor reflex bradycardia after activation of preganglionic (PG) cells in the nucleus ambiguous (NAmb). Previous and present findings show that, during the defence-like reaction triggered by rostral cuneiform nucleus ( $\mathrm{rCnF}$ ) disinhibition, activation of (i) direct and indirect (through the dorsolateral PAG, dIPAG) projections to the LPGi and (ii) indirect projections to the RMg, both located in the intermediate B3 (iB3) region, produces the release of $5-\mathrm{HT}$ into the NTS. 5-HT downstream stimulates $5-\mathrm{HT}_{3}$ receptors (small grey circle) localized presynaptically on gastrointestinal (GI) vagal glutamatergic afferents in the NTS. The resulting facilitation of glutamate release ends with the excitation of NTS GABAergic interneurons, which, in turn, inhibit baroreflex bradycardia through the stimulation of $\mathrm{GABA}_{A}$ receptors (small black circle) on barosensitive a cells. "+" indicates excitatory effect; "_" indicates inhibitory effect

Though a higher proportion of 5-HT cells were activated in the LPGi than in the RMg, there was a marked increase of cFos in both regions. Thus, we microinjected muscimol or 8-OH-DPAT in either LPGi or RMg and we pooled our data. In this context, it is relevant that muscimol-induced inactivation of the intermediate portion of the B3 region suppressed almost completely the inhibitory effect of rostral cuneiform disinhibition on vagal baroreflex response range and BRS.

None of the data discussed above specifically demonstrated the involvement of $5-\mathrm{HT}$ neurons in the $\mathrm{B} 3$ area. The $5-\mathrm{HT}_{1 \mathrm{~A}}$ receptor is often located presynaptically as an autoreceptor, on the perikaryon and dendritic spines of 5-HT-containing neurons. It is also expressed as a heteroreceptor on neurons receiving input from 5-HT neurons. 8-OH-DPAT is a highly selective and centrally active potent ligand preferentially binding to the somatodendritic $5-\mathrm{HT}_{1 \mathrm{~A}}$ autoreceptor (Hjorth \& Magnusson, 1988; Middlemiss \& Fozard, 1983). Consequently, the release of $5-\mathrm{HT}$ from the $5-\mathrm{HT}$ nerve endings is diminished. In an in vitro study on dorsal raphé slices, $92 \%$ of neurons responding to 8-OH-DPAT contain 5-HT and the application of 8-OH-DPAT inhibits action potential firing in these cells (YasufukuTakano et al., 2008). In line with these studies, 8-OH-DPAT prevents the 5-HT-induced shivering during cooling when administered in the LPGi (Brown et al., 2008) and reduces thermoregulatory responses to peripheral thermal challenges when given into the $\mathrm{RMg}$ (Berner et al., 1999). Here, we observed that 8-OH-DPAT in B3 had a similar preventive action on the baroreflex bradycardia inhibition induced by rostral cuneiform disinhibition to that obtained after muscimol. Even if we cannot exclude the possibility that 8-OH-DPAT could also affect $5-\mathrm{HT}_{1 \mathrm{~A}}$ heteroreceptors located on non-5-HT-IR neurons, our overall data strongly suggest the key role is played by $5-\mathrm{HT}$-IR neurons of the LPGi and RMg in the intermediate B3 in baroreflex inhibition during the defence reaction.

These cells are most presumably responsible for $5-\mathrm{HT}$ release into the NTS. Previously we showed that the baroreflex inhibition induced 
by the dorsolateral PAG involved the activation of NTS $5-\mathrm{HT}_{3}$ receptors (Bernard et al., 2008; Comet et al., 2004, 2005; Sévoz-Couche et al., 2003). Both the microinjection of granisetron into the NTS and the use of mice lacking the $5-\mathrm{HT}_{3}$ receptor prevented dorsolateral PAG-induced inhibition of chemoreflex responses (Zafar et al., 2018). In the same manner, the cuneiform-induced baroreflex inhibition was prevented by the blockade of NTS $5-\mathrm{HT}_{3}$ receptors with granisetron and was also not observed in $5-\mathrm{HT}_{3}$ receptor knockout mice. These results show the role of $5-\mathrm{HT}_{3}$ receptors play a role in the cuneiforminduced baroreflex inhibition, presumably at the level of NTS location. Another elegant and selective approach to confirm these results could be the use of NTS microinjections of a viral vector for $5-\mathrm{HT}_{3}$ gene silencing.

In conclusion, our results support and extend data in Netzer et al. (2011) that showed that rostral cuneiform nucleus stimulation produced typical defence responses (an increase in HR and BP associated with a reduction in the baroreflex cardiac response) through activation of the dorsolateral PAG, a key area of the defence reaction (Bandler \& Carrive, 1988). We found here that rostral cuneiform nucleus-evoked baroreflex inhibition involve direct and indirect (at least through the dorsolateral PAG column) activation of intermediate B3 5-HT-containing neurons to release $5-\mathrm{HT}$ into the NTS and activate $5-\mathrm{HT}_{3}$ receptors, ultimately inhibiting the baroreflexmediated vagal bradycardia (Figure 8). These data bring new insights in the multiple mechanisms involved in baroreflex prevention during the defence reaction.

Direct and indirect links to B3 appear to be a safety mechanism for baroreflex inhibition, which is vital to allow cardiac output increase and blood flow redistribution when BP increases during stress. On the other hand, as baroreflex failure is a risk factor for ventricular arrhythmia (Brouillard et al., 2020), the existence of multiple pathways leading to baroreflex dysfunction may explain why $20 \%$ to $40 \%$ of sudden cardiac deaths are reported to be precipitated by strong acute stressors (Vlastelica, 2008).

Finally, it is important to note that systemic use of granisetron-a potent anti-emetic (Audhuy et al., 1996) with a highly safe profile (Aapro, 2004)-known to cross the blood-brain barrier (Huang et al., 1998), was found in a previous study to prevent baroreflex inhibition during stress (Sévoz-Couche et al., 2013). Therefore, treatment with granisetron could be used to restore parasympathetic activity and, thus, reduce the likelihood of adverse cardiac events induced by stress.

\section{ACKNOWLEDGEMENT}

The authors thank Julie Schneider for proofreading the manuscript. We thank the Association Sorbonne Université and Institut National de la Santé et de la Recherche Médicale (INSERM) for their support.

\section{AUTHOR CONTRIBUTIONS}

C.S.-C. contributed to the conceptualization, investigation and methodology of the study, writing of the original draft and writing of the review and editing the manuscript and F.N. to the data curation and formal analysis of the study.

\section{CONFLICT OF INTEREST}

The authors declare no conflicts of interest.

\section{DECLARATION OF TRANSPARENCY AND SCIENTIFIC RIGOUR}

This Declaration acknowledges that this paper adheres to the principles for transparent reporting and scientific rigour of preclinical research as stated in the BJP guidelines for Design \& Analysis, Immunoblotting and Immunochemistry and Animal Experimentation and as recommended by funding agencies, publishers and other organizations engaged with supporting research.

\section{DATA AVAILABILITY STATEMENT}

The data that support the findings of this study are available from the corresponding author upon reasonable request. Some data may not be made available because of privacy or ethical restrictions.

\section{REFERENCES}

Aapro, M. (2004). Granisetron: An update on its clinical use in the management of nausea and vomiting. The Oncologist, 9(6), 673-686. https:// doi.org/10.1634/theoncologist.9-6-673

Abols, L. A., \& Basbaum, A. I. (1981). Afferent connections of the rostral medulla of the cat: A neural substrate for midbrainmedullary interactions in the modulation of pain. The Journal of Comparative Neurology, 201, 285-297. https://doi.org/10.1002/cne. 902010211

Alexander, S. P. H., Christopoulos, A., Davenport, A. P., Kelly, E., Mathie, A., Peters, J. A., Veale, E. L., Armstrong, J. F., Faccenda, E., Harding, S. D., \& Pawson, A. J. (2019). The Concise Guide to PHARMACOLOGY 2019/20: G-protein coupled receptors. British Journal of Pharmacology, 176, S21-S141.

Alexander, S. P. H., Mathie, A., Peters, J. A., Veale, E. L., Striessnig, J., Kelly, E., Armstrong, J. F., Faccenda, E., Harding, S. D., Pawson, A. J., \& Sharman, J. L. (2019). The Concise Guide to PHARMACOLOGY 2019/20: Ion channels. British Journal of Pharmacology, 176, S142-S228.

Alexander, S. P. H., Roberts, R. E., Broughton, B. R. S., Sobey, C. G., George, C. H., Stanford, S. C., Cirino, G., Docherty, J. R., Giembycz, M. A., Hoyer, D., Insel, P. A., Izzo, A. A., Ji, Y., MacEwan, D. J., Mangum, J., Wonnacott, S., \& Ahluwalia, A. (2018). Goals and practicalities of immunoblotting and immunohistochemistry: A guide for submission to the British Journal of Pharmacology. British Journal of Pharmacology, 175, 407-411. https://doi.org/10.1111/bph. 14112

Anderson, F. L., \& Brown, A. M. (1967). Pulmonary vasoconstriction elicited by stimulation of the hypothalamic integrative area for the defense reaction. Circulation Research, 21(5), 747-756. https://doi. org/10.1161/01.RES.21.5.747

Audhuy, B., Cappelaere, P., Martin, M., Cervantes, A., Fabbro, M., Rivière, A., ... Seitz, J. F. (1996). A double-blind, randomised comparison of the anti-emetic efficacy of two intravenous doses of dolasetron mesilate and granisetron in patients receiving high dose cisplatin chemotherapy. European Journal of Cancer, 32A(5), 807-813.

Babic, T., \& Ciriello, J. (2004). Medullary and spinal cord projections from cardiovascular responsive sites in the rostral ventromedial medulla. The Journal of Comparative Neurology, 469(3), 391-412. https://doi. org/10.1002/cne.11024

Bandler, R., \& Carrive, P. (1988). Integrated defence reaction elicited by excitatory amino acid microinjection in the midbrain periaqueductal grey region of the unrestrained cat. Brain Research, 439(1-2), 95-106. https://doi.org/10.1016/0006-8993(88)91465-5 
Bernard, J. F., Netzer, F., Gau, R., Hamon, M., Laguzzi, R., \& SévozCouche, C. (2008). Critical role of B3 serotonergic cells in baroreflex inhibition during the defense reaction triggere by dorsal periaqueductal gray stimulation. The Journal of Comparative Neurology, 506, 108-121. https://doi.org/10.1002/cne.21532

Berner, N. J., Grahn, D. A., \& Heller, H. C. (1999). 8-OH-DPAT-sensitive neurons in the nucleus raphe magnus modulate thermoregulatory output in rats. Brain Research, 831(1-2), 155-164. https://doi.org/10. 1016/S0006-8993(99)01426-2

Blugeot, A., Rivat, C., Bouvier, E., Molet, J., Mouchard, A., Zeau, B., Bernard, C., Benoliel, J. J., \& Becker, C. (2011). Vulnerability to depression: From brain neuroplasticity to identification of biomarkers. The Journal of Neuroscience, 31, 12889-12899. https://doi.org/10.1523/ JNEUROSCI.1309-11.2011

Brouillard, C., Carrive, P., \& Sévoz-Couche, C. (2020). Social defeat: Vagal reduction and vulnerability to ventricular arrhythmias. Neurobiology of Stress, 13, 100245. https://doi.org/10.1016/j.ynstr.2020.100245

Brown, J. W., Sirlin, E. A., Benoit, A. M., Hoffman, J. M., \& Darnall, R. A. (2008). Activation of $5-\mathrm{HT}_{1 \mathrm{~A}}$ receptors in medullary raphé disrupts sleep and decreases shivering during cooling in the conscious piglet. American Journal of Physiology. Regulatory, Integrative and Comparative Physiology, 294(3), 884-894.

Cameron, A. A., Khan, I. A., Westlund, K. N., \& Willis, W. D. (1995). The efferent projections of the periaqueductal gray in the rat: A Phaseolus vulgaris-leucoagglutinin study. II. Descending projections. The Journal of Comparative Neurology, 351, 585-601. https://doi.org/10.1002/ cne.903510408

Carlton, S. M., Leichnetz, G. R., Young, E. G., \& Mayer, D. J. (1983). Supramedullary afferents of the nucleus raphe magnus in the rat: $A$ study using the transcannula HRP gel and autoradiographic techniques. The Journal of Comparative Neurology, 214(1), 43-58. https:// doi.org/10.1002/cne.902140105

Carmichael, J., Cantwell, B. M., Edwards, C. M., Zussman, B. D., Thompson, S., Rapeport, W. G., \& Harris, A. L. (1989). A pharmacokinetic study of granisetron (BRL 43694A), a selective $5-\mathrm{HT}_{3}$ receptor antagonist: Correlation with anti-emetic response. Cancer Chemotherapy and Pharmacology, 24(1), 45-49. https://doi.org/10.1007/ BF00254104

Comet, M. A., Laguzzi, R., Hamon, M., \& Sévoz-Couche, C. (2005). Functional interaction between nucleus tractus solitarius NK1 and $5-\mathrm{HT}_{3}$ receptors in the inhibition of baroreflex in rats. Cardiovascular Research, 65, 930-939. https://doi.org/10.1016/j.cardiores.2004. 11.012

Comet, M. A., Sévoz-Couche, C., Hanoun, N., Hamon, M., \& Laguzzi, R. (2004). 5-HT-mediated inhibition of cardiac baroreceptor reflex response during defense reaction in the rat. American Journal of Physiology. Heart and Circulatory Physiology, 287, H1641-H1649. https:// doi.org/10.1152/ajpheart.01204.2003

Crestani, C. (2016). Emotional stress and cardiovascular complications in animal models: A review of the influence of stress type. Frontiers in Physiology, 7, 251-259.

Curtis, M. J., Alexander, S., Cirino, G., Docherty, J. R., George, C. H., Giembycz, M. A., Hoyer, D., Insel, P. A., Izzo, A. A., Ji, Y., MacEwan, D. J., Sobey, C. G., Stanford, S. C., Teixeira, M. M., Wonnacott, S., \& Ahluwalia, A. (2018). Experimental design and analysis and their reporting II: Updated and simplified guidance for authors and peer reviewers. British Journal of Pharmacology, 175, 987-993. https://doi.org/10.1111/bph.14153

Dampney, R. A., \& Horiuchi, J. (2003). Functional organisation of central cardiovascular pathways: Studies using $c$-fos gene expression. Progress in Neurobiology, 71(5), 359-384. https://doi.org/10.1016/j.pneurobio. 2003.11.001

DiMicco, J. A., Stotz-Potter, E. H., Monroe, A. J., \& Morin, S. M. (1996). Role of the dorsomedial hypothalamus in the cardiovascular response to stress. Clinical and Experimental Pharmacology \& Physiology, 23(2), 171-176. https://doi.org/10.1111/j.1440-1681.1996.tb02592.x

Foo, H., \& Mason, P. (2003). Brainstem modulation of pain during sleep and waking. Sleep Medicine Reviews, 7(2), 145-154. https://doi.org/10. 1053/smrv.2002.0224

Gao, K., \& Mason, P. (2000). Serotonergic raphe magnus cells that respond to noxious tail heat are not ON or OFF cells. Journal of Neurophysiology, 84, 719-1725.

Gardner, K. L., Thrivikraman, K. V., Lightman, S. L., Plotsky, P. M., \& Lowry, C. A. (2005). Early life experience alters behavior during social defeat: Focus on serotonergic systems. Neuroscience, 136(1), 181-191. https://doi.org/10.1016/j.neuroscience.2005.07.042

Gau, R., Sévoz-Couche, C., Laguzzi, R., Hamon, M., \& Bernard, J. F. (2009). Inhibition of cardiac baroreflex by noxious thermal stimuli: A key role for lateral paragigantocellular serotonergic cells. Pain, 146(3), 315-324. https://doi.org/10.1016/j.pain.2009.09.018

Hamon, M., Fattaccini, C. M., Adrien, J., Gallissot, M. C., Martin, P., \& Gozlan, H. (1988). Alterations of central serotonin and dopamine turnover in rats treated with ipsapirone and other 5-hydroxytryptamine1A agonists with potential anxiolytic properties. The Journal of Pharmacology and Experimental Therapeutics, 246(2), 745-752.

Head, G., \& McCarty, R. (1987). Vagal and sympathetic components of the heart rate range and gain of the baroreceptor-heart rate reflex in conscious rats. Journal of the Autonomic Nervous System, 21(2-3), 203-213. https://doi.org/10.1016/0165-1838(87)90023-3

Hermann, D. M., Luppi, P. H., Peyron, C., Hinckel, P., \& Jouvet, M. (1997). Afferent projections to the rat nuclei raphe magnus, raphe pallidus and reticularis gigantocellularis pars $\alpha$ demonstrated by iontophoretic application of choleratoxin (subunit b). Journal of Chemical Neuroanatomy, 13, 1-21. https://doi.org/10.1016/S0891-0618(97)00019-7

Hjorth, S., \& Magnusson, T. (1988). The 5- $\mathrm{HT}_{1 \mathrm{~A}}$ receptor agonist, 8-OHDPAT, preferentially activates cell body $5-\mathrm{HT}$ autoreceptors in rat brain in vivo. Naunyn-Schmiedeberg's Archives of Pharmacology, 338(5), 463-471. https://doi.org/10.1007/BF00179315

Hoyer, D. (1990). Serotonin 5- $\mathrm{HT}_{3}, 5-\mathrm{HT}_{4}$, and 5-HT-M receptors. Neuropsychopharmacology, 3(5-6), 371-383.

Huang, C. T., Chen, K. C., Chen, C. F., \& Tsai, T. H. (1998). Simultaneous measurement of blood and brain microdialysate of granisetron in rat by high-performance liquid chromatography with fluorescence detection. Journal of Chromatography. B, Biomedical Sciences and Applications, 716(1-2), 251-255. https://doi.org/10.1016/S0378-4347(98) 00274-6

Johnson, P. L., Truitt, W. A., Fitz, S. D., Lowry, C. A., \& Shekhar, A. (2008). Neural pathways underlying lactate-induced panic. Neuropsychopharmacology, 33(9), 2093-2107. https://doi.org/10. 1038/sj.npp.1301621

Johnston, G. A., Curtis, D. R., De Groat, W. C., \& Duggan, A. W. (1968). Central actions of ibotenic acid and muscimol. Biochemical Pharmacology, 17(12), 2488-2489. https://doi.org/10.1016/0006-2952(68) 90141-X

Koyama, N., Nishio, T., \& Yokota, T. (2000). Non-serotonergic midbrain neurons are involved in picrotoxin-induced analgesia. An immunohistochemical study in the rat. Neuroscience Letters, 291(3), 147-150. https://doi.org/10.1016/S0304-3940(00)01387-2

Lilley, E., Stanford, S. C., Kendall, D. E., Alexander, S. P., Cirino, G., Docherty, J. R., George, C. H., Insel, P. A., Izzo, A. A., Ji, Y., Panettieri, R. A., Sobey, C. G., Stefanska, B., Stephens, G., Teixeira, M., \& Ahluwalia, A. (2020). ARRIVE 2.0 and the British Journal of Pharmacology: Updated guidance for 2020. British Journal of Pharmacology. https://doi.org/10.1111/bph.15178

Lindvall, K., Kahan, T., de Faire, U., Ostergren, J., \& Hjemdahl, P. (1991). Stress-induced changes in blood pressure and left ventricular function in mild hypertension. Clinical Cardiology, 14(2), 125-132. https://doi. org/10.1002/clc.4960140208 
Lkhagvasuren, B., Oka, T., Nakamura, Y., Hayashi, H., Sudo, N., \& Nakamura, K. (2014). Distribution of Fos-immunoreactive cells in rat forebrain and midbrain following social defeat stress and diazepam treatment. Neuroscience, 272, 34-57. https://doi.org/10.1016/j. neuroscience.2014.04.047

Martin, D. S., Appelt, C., Rodrigo, M. C., \& Egland, M. C. (1996). Acute stress increases venomotor tone in conscious rats. The American Journal of Physiology, 271(4 Pt 2), H1375-H1383. https://doi.org/10. 1152/ajpheart.1996.271.4.H1375

Middlemiss, D. N., \& Fozard, J. R. (1983). 8-Hydroxy-2-(di-n-propylamino)tetralin discriminates between subtypes of the $5-\mathrm{HT}_{1}$ recognition site. European Journal of Pharmacology, 90(1), 151-153. https://doi.org/10. 1016/0014-2999(83)90230-3

Netzer, F., Bernard, J. F., Verberne, A. J., Hamon, M., Camus, F., Benoliel, J. J., \& Sévoz-Couche, C. (2011). Brain circuits mediating baroreflex bradycardia inhibition in rats: An anatomical and functional link between the cuneiform nucleus and the periaqueductal grey. The Journal of Physiology, 589, 2079-2091. https://doi.org/10.1113/ jphysiNetzerol.2010.203737

Niérat, M. C., Laviolette, L., Hudson, A., Similowski, T., \& Sévoz-Couche, C. (2017). Experimental dyspnea as a stressor: differential cardiovegetative responses to inspiratory threshold loading in healthy men and women. J Appl Physiol (1985), 123(1), 205-212.

Nosaka, S. (1996). Modifications of arterial baroreflexes: Obligatory roles in cardiovascular regulation in stress and poststress recovery. The Japanese Journal of Physiology, 46(4), 271-288. https://doi.org/10. 2170/jjphysiol.46.271

Ootsuka, Y., \& Blessing, W. W. (2006). Activation of 5- $\mathrm{HT}_{1 \mathrm{~A}}$ receptors in rostral medullary raphé inhibits cutaneous vasoconstriction elicited by cold exposure in rabbits. Brain Research, 1074, 252-261.

Palkovits, M., Mezey, E., Eskay, R. L., \& Brownstein, M. J. (1986). Innervation of the nucleus of the solitary tract and the dorsal vagal nucleus by thyrotropin-releasing hormone-containing raphe neurons. Brain Research, 373(1-2), 246-251. https://doi.org/10.1016/0006-8993 (86) $90338-0$

Paxinos, P., \& Watson, C. (2005). The rat brain in stereotaxic coordinates (5th ed.). London: Academic Press.

Percie du Sert, N., Hurst, V., Ahluwalia, A., Alam, S., Avey, M. T., Baker, M., Browne, W. J., Clark, A., Cuthill, I. C., Dirnagl, U., Emerson, M., Garner, P., Holgate, S. T., Howells, D. W., Karp, N. A., Lazic, S. E., Lidster, K., MacCallum, C. J., Macleod, M., ... Würbel, H. (2020). The ARRIVE guidelines 2.0: Updated guidelines for reporting animal research. PLoS Biology, 18(7), e3000410. https://doi.org/10.1371/ journal.pbio.3000410

Pollano, A., Trujillo, V., \& Suárez, M. M. (2018). How does early maternal separation and chronic stress in adult rats affect the immunoreactivity of serotonergic neurons within the dorsal raphe nucleus? Stress, 21(1), 59-68. https://doi.org/10.1080/10253890.2017.1401062

Saad, M. A., Huerta, F., Trancard, J., \& Elghozi, J. L. (1989). Effects of middle cerebral artery occlusion on baroreceptor reflex control of heart rate in the rat. Journal of the Autonomic Nervous System, 27(2), 165-172. https://doi.org/10.1016/0165-1838(89)90098-2

Schaffar, N., Kessler, J. P., Bosler, O., \& Jean, A. (1988). Central serotonergic projections to the nucleus tractus solitarii: Evidence from a double labeling study in the rat. Neuroscience, 26, 951-958.

Schulte, W., \& Neus, H. (1983). Hemodynamics during emotional stress in borderline and mild hypertension. European Heart Journal, 4(11), 803-809. https://doi.org/10.1093/oxfordjournals.eurheartj.a061401

Sévoz-Couche, C., Brouillard, C., Camus, F., Laude, D., De Boer, S. F., Becker, C., \& Benoliel, J.-J. (2013). Involvement of the dorsomedial hypothalamus and the nucleus tractus solitarii in chronic cardiovascular changes associated with anxiety in rats. The Journal of Physiology, 591, 1871-1887. https://doi.org/10.1113/jphysiol.2012.247791
Sévoz-Couche, C., Comet, M.-A., Hamon, M., \& Laguzzi, R. (2003). Role of nucleus tractus solitarius $5-\mathrm{HT}_{3}$ receptors in the defense reactioninduced inhibition of the aortic baroreflex in rats. Journal of Neurophysiology, 90(4), 2521-2530. https://doi.org/10.1152/jn.00275.2003

Spiacci, A. Jr., Coimbra, N. C., \& Zangrossi, H. Jr. (2012). Differential involvement of dorsal raphe subnuclei in the regulation of anxietyand panic-related defensive behaviors. Neuroscience, 227, 350-360. https://doi.org/10.1016/j.neuroscience.2012.09.061

Thor, K. B., \& Helke, C. J. (1987). Serotonin- and substance P-containing projections to the nucleus tractus solitarii of the rat. The Journal of Comparative Neurology, 265, 275-293. https://doi.org/10.1002/cne. 902650210

Vaschillo, E. G., Vaschillo, B., \& Lehrer, P. M. (2006). Characteristics of resonance in heart rate variability stimulated by biofeedback. Applied Psychophysiology and Biofeedback, 31(2), 129-142. https://doi.org/10. 1007/s10484-006-9009-3

Vlastelica, M. (2008). Emotional stress as a trigger in sudden cardiac death. Psychiatria Danubina, 20(3), 411-414.

Wilson, T. E., \& Crandall, C. G. (2011). Effect of thermal stress on cardiac function. Exercise and Sport Sciences Reviews, 39(1), 12-17. https://doi. org/10.1097/JES.0b013e318201eed6

Yasufuku-Takano, J., Nakajima, S., \& Nakajima, Y. (2008). Morphological and physiological properties of serotonergic neurons in dissociated cultures from the postnatal rat dorsal raphe nucleus. Journal of Neuroscience Methods, 167(2), 258-267. https://doi.org/10.1016/j. jneumeth.2007.08.018

Yin, J. B., Wu, H. H., Dong, Y. L., Zhang, T., Wang, J., Zhang, Y., Wei, Y. Y., Lu, Y. C., Wu, S. X., Wang, W., \& Li, Y. Q. (2014). Neurochemical properties of BDNF-containing neurons projecting to rostral ventromedial medulla in the ventrolateral periaqueductal gray. Frontiers in Neural Circuits, 8, 137-143.

Zafar, T., Brouillard, C., Lanfumey, L., \& Sévoz-Couche, C. (2018). A hypothalamo-midbrain-medullary pathway involved in the inhibition of the respiratory chemoreflex response induced by potassium cyanide in rodents. Neuropharmacology, 128, 152-167. https://doi.org/10. 1016/j.neuropharm.2017.09.036

Zagon, A. (1993). Innervation of serotonergic medullary raphe neurons from cells of the rostral ventrolateral medulla in rats. Neuroscience, 55 (3), 849-867. https://doi.org/10.1016/0306-4522(93)90446-M

Zeitz, K. P., Guy, N., Malmberg, A. B., Dirajlal, S., Martin, W. J., Sun, L., Bonhaus, D. W., Stucky, C. L., Julius, D., \& Basbaum, A. I. (2002). The $5-\mathrm{HT}_{3}$ subtype of serotonin receptor contributes to nociceptive processing via a novel subset of myelinated and unmyelinated nociceptors. The Journal of Neuroscience, 22, 1010-1019. https://doi. org/10.1523/JNEUROSCI.22-03-01010.2002

Zemlan, F. P., \& Behbehani, M. M. (1988). Nucleus cuneiformis and pain modulation: Anatomy and behavioral pharmacology. Brain Research, 453(1-2), 89-102. https://doi.org/10.1016/0006-8993(88)90146-1

\section{SUPPORTING INFORMATION}

Additional supporting information may be found online in the Supporting Information section at the end of this article.

How to cite this article: Netzer F, Sévoz-Couche C. Rostral cuneiform nucleus and the defence reaction: Direct and indirect midbrain-medullary 5-HT mechanisms in baroreflex inhibition. Br J Pharmacol. 2021;178:1819-1835. https://doi. org/10.1111/bph.15406 